\title{
A systematic review and meta-analysis of the use of renin- angiotensin system drugs and COVID-19 clinical outcomes: What is the evidence so far?
}

\author{
Amanj Kurdi $^{1,2}$ (D) $\mid$ Nouf Abutheraa ${ }^{1}$ | Lina Akil ${ }^{1}$ | Brian Godman ${ }^{1,3,4}$
}

\author{
${ }^{1}$ Strathclyde Institute of Pharmacy \\ and Biomedical Sciences, University of \\ Strathclyde, Glasgow, UK \\ ${ }^{2}$ Department of Pharmacology and \\ Toxicology, College of Pharmacy, Hawler \\ Medical University, Kurdistan Region \\ Government, Erbil, Iraq \\ ${ }^{3}$ Division of Clinical Pharmacology, \\ Karolinska Institute, Stockholm, Sweden \\ ${ }^{4}$ Division of Public Health Pharmacy and \\ Management, School of Pharmacy, Sefako \\ Makgatho Health Sciences University, \\ Pretoria, South Africa \\ Correspondence \\ Amanj Kurdi, Strathclyde Institute of \\ Pharmacy and Biomedical Science, \\ University of Strathclyde, 161 Cathedral \\ Street, Glasgow G4 ORE, UK. \\ Email:amanj.baker@strath.ac.uk
}

\begin{abstract}
Conflicting evidence exists about the effect of angiotensin-converting enzyme inhibitors (ACEls)/angiotensin receptor blockers (ARBs) on COVID-19 clinical outcomes. We aimed to provide a comprehensive/updated evaluation of the effect of ACEIS/ARBs on COVID-19-related clinical outcomes, including exploration of interclass differences between ACEls and ARBs, using a systematic review/metaanalysis approach conducted in Medline (OVID), Embase, Scopus, Cochrane library, and medRxiv from inception to 22 May 2020. English studies that evaluated the effect of ACEIs/ARBs among patients with COVID-19 were included. Studies' quality was appraised using the Newcastle-Ottawa Scale. Data were analyzed using the random-effects modeling stratified by exposure (ACEIs/ARBs, ACEls, and ARBs). Heterogeneiity was assessed using $I^{2}$ statistic. Several subgroup analyses were conducted to explore the impact of potential confounders. Overall, 27 studies were eligible. The pooled analyses showed nonsignificant associations between ACEIs/ARBs and death (OR:0.97, 95\% Cl:0.75,1.27), ICU admission (OR:1.09;95\% Cl:0.65,1.81), death/ICU admission (OR:0.67; 95\%Cl:0.52,0.86), risk of COVID-19 infection (OR:1.01; 95\%Cl:0.93,1.10), severe infection (OR:0.78; 95\% Cl:0.53,1.15), and hospitalization (OR:1.15; 95\% Cl:0.81,1.65). However, the subgroup analyses indicated significant association between ACEls/ARBs and hospitalization among USA studies (OR:1.59; 95\%Cl:1.03,2.44), peer-reviewed (OR:1.93, 95\%Cl:1.38,2.71), good quality and studies which reported adjusted measure of effect (OR:1.30, 95\% Cl:1.10,1.50). Significant differences were found between ACEls and ARBs with the latter being significantly associated with lower risk of acquiring COVID-19 infection (OR:0.24; $95 \% \mathrm{Cl}$ : 0.17,0.34). In conclusion, high-quality evidence exists for the effect of ACEls/ ARBs on some COVID-19 clinical outcomes. For the first time, we provided evidence, albeit of low quality, on interclass differences between ACEls and ARBs for some of the reported clinical outcomes.
\end{abstract}

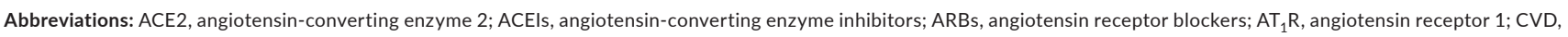
cardiovascular disease.

This is an open access article under the terms of the Creative Commons Attribution License, which permits use, distribution and reproduction in any medium, provided the original work is properly cited.

(c) 2020 The Authors. Pharmacology Research \& Perspectives published by John Wiley \& Sons Ltd, British Pharmacological Society and American Society for Pharmacology and Experimental Therapeutics. 


\section{KEYWORDS}

angiotensin receptor blockers, angiotensin-converting enzyme inhibitors, coronavirus,

COVID-19 infection, severe acute respiratory syndrome coronavirus 2

\section{1 | INTRODUCTION}

Soon after the report of first clusters of COVID-19 cases in China in December 2019, concerns were raised among clinicians and investigators that angiotensin-converting enzyme inhibitors (ACEIs) and angio tensin receptor blockers (ARBs) might increase susceptibility to COVID19 infection and the likelihood of severe and fatal COVID-19 illness. ${ }^{1}$ These concerns are based on the concept that angiotensin-conve rting enzyme 2 (ACE2), an enzyme potentially upregulated by ACEls/ ARBs use, is the viral entry receptor that COVID-19 uses to enter lung cell, ${ }^{2}$ coupled with the observation of high prevalence of hypertension and other cardiovascular comorbidities among COVID-19 patients who have poor outcomes. ${ }^{3}$ Consequently, it was speculated that due to considerable prescription of ACEls/ARBs to treat cardiovascular diseases (CVD), this would adversely affect outcomes from COVID-19 ${ }^{4}$ with underlying cardiac and kidney diseases already associated with poorer outcomes. ${ }^{3,5,6}$ Consequently, care to avoid treatments that well add to this.

Unsurprisingly, discussions regarding the potential impact of ACEIs/ ARBs have resulted in anxiety, which might cause patients and clinicians to discontinue or stop these medications. ${ }^{7}$ This should be avoided as there will be harm from the indiscriminate withdrawal of ACEIs/ARBs. ${ }^{8}$ This concern is complicated by uncertainty surrounding the upregulation of ACE2 by ACEIs/ARBs. ${ }^{9}$ Furthermore, the paradoxical protective role of ACEIs/ARBs in COVID-19 patients is also being proposed. ${ }^{10}$ Due to these controversial findings, and despite consistent and reassuring recommendations for the continued use of ACEIs/ARBs in COVID-19 patients issued by International Societies, ${ }^{11}$ these concerns remain. We wish to address this as we have already seen the impact that inappropriate endorsement of treatments can have on morbidity and mortality. Early endorsement of hydroxychloroquine resulted in drug shortages for other indications, price hikes, increased adverse drug reactions, and deaths from suicides. ${ }^{12,13}$ However, subsequent studies failed to show clinical benefit resulting in the World Health Organisation (WHO) and the National Institute of Health (NIH) in the USA stopping the hydroxychloroquine arm in their studies. ${ }^{14-16}$ A similar situation has been seen with lopinavir/ritonavir. ${ }^{15}$ Consequently it is imperative that any considerations regarding management are evidence based.

We are aware that several observational studies have been conducted to address these concerns. However, these studies have reported

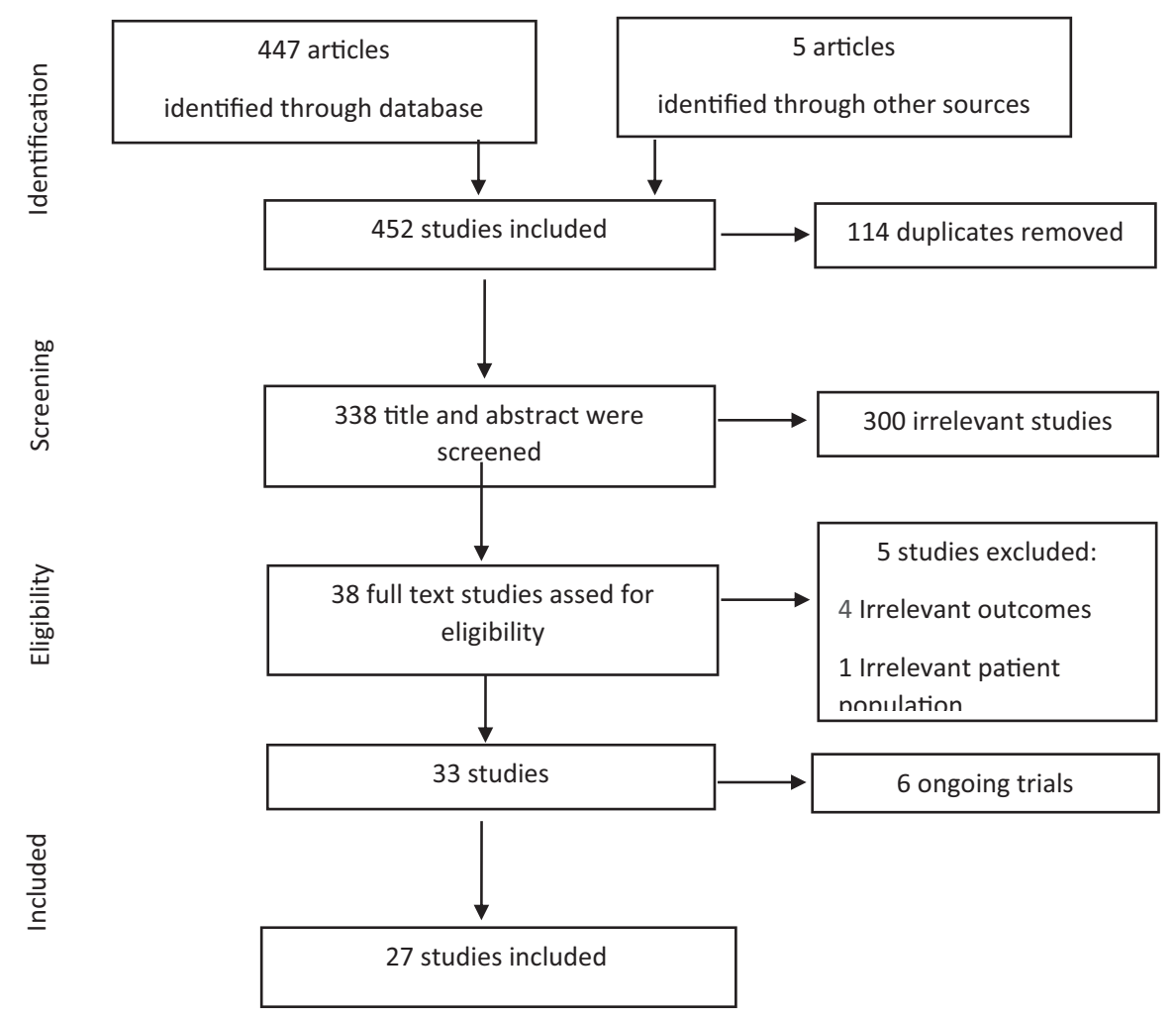

FIGURE 1 Study selection 

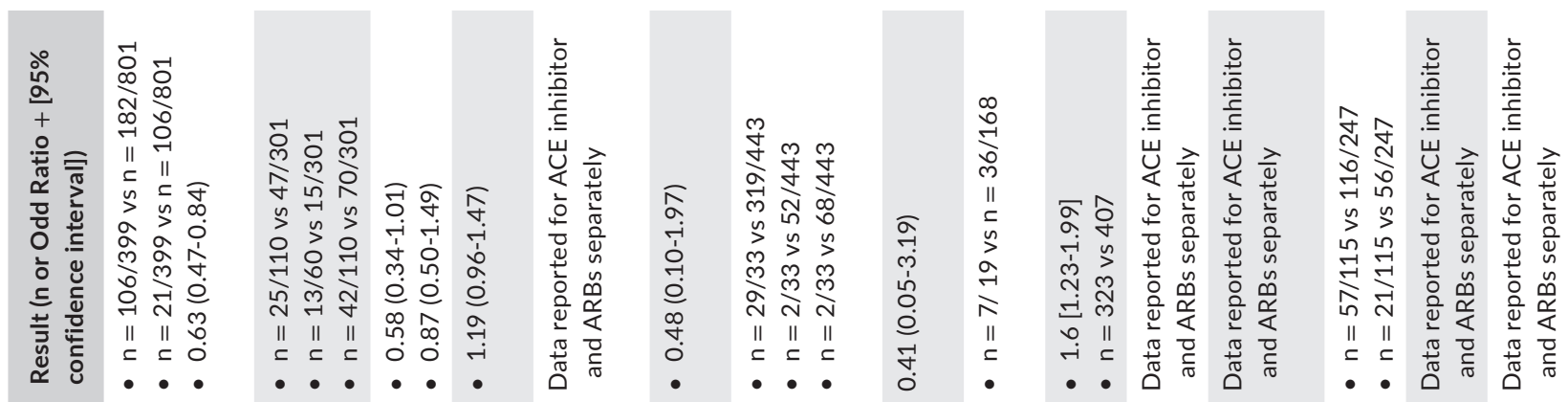

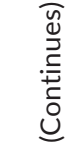
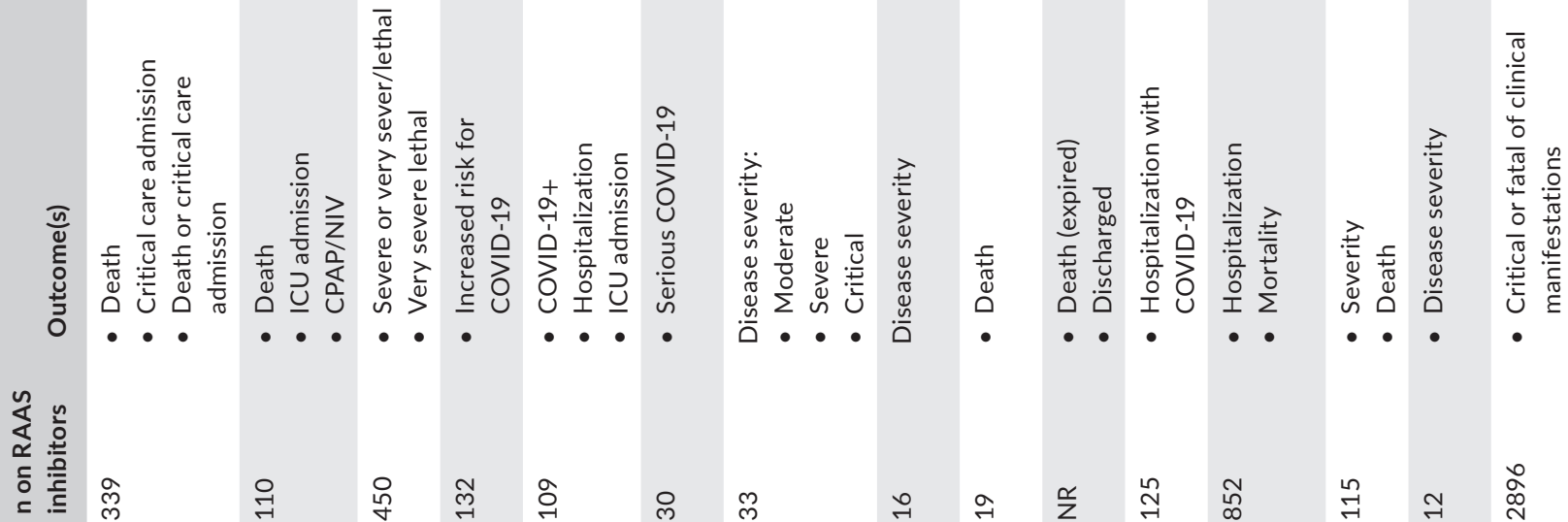

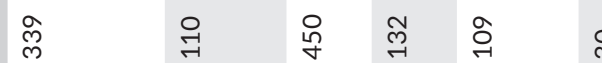

잉

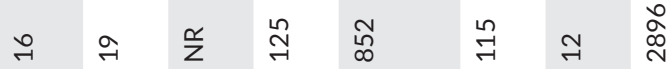

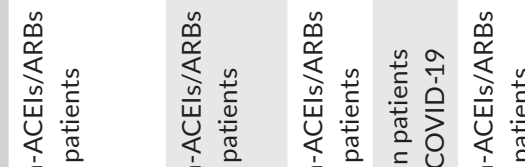

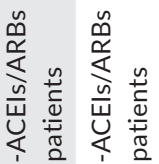

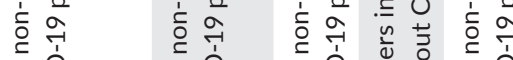



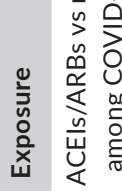

品

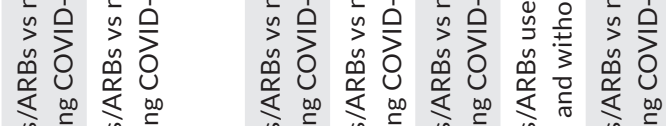

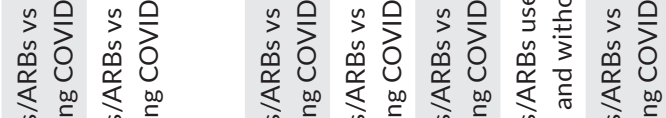

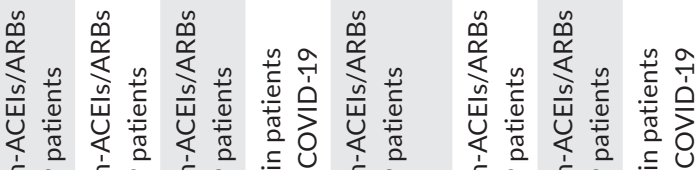

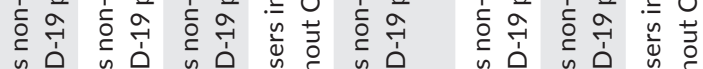

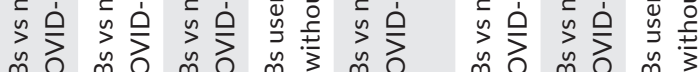

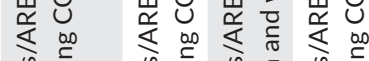

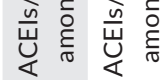

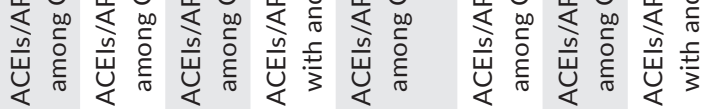

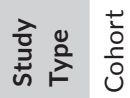

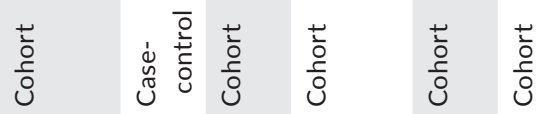

喜

焉 $=$ ฐ

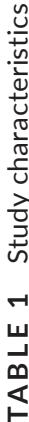

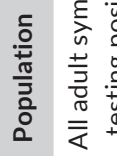

F

高 啇

$\stackrel{9}{4}$

莴 覓 䓀

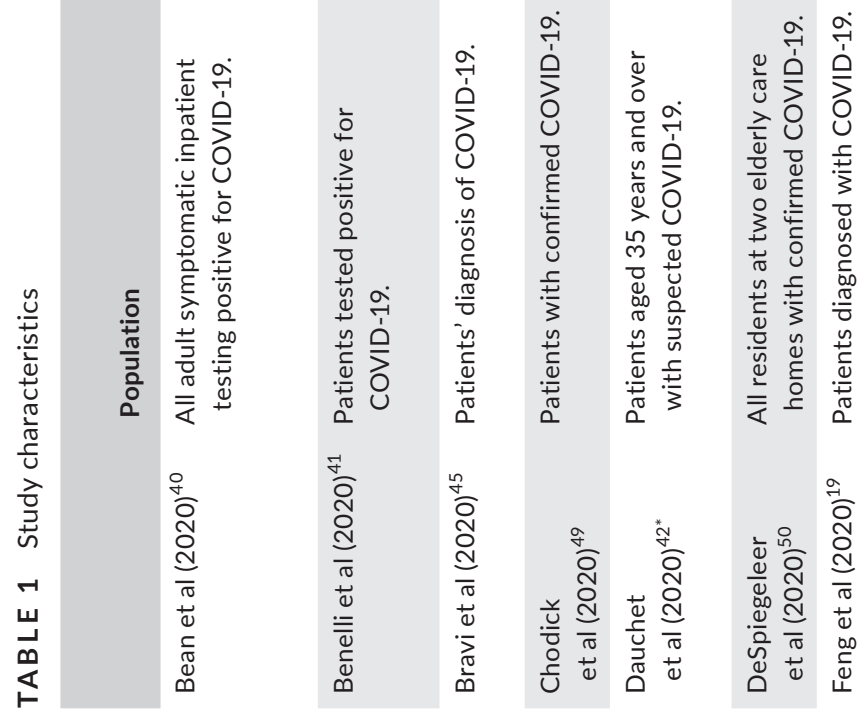

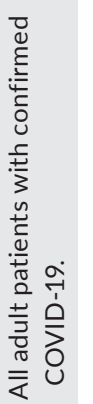

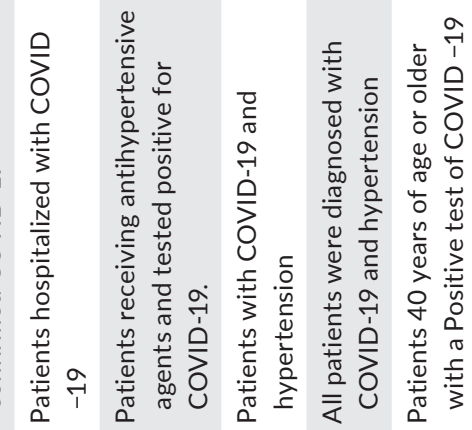

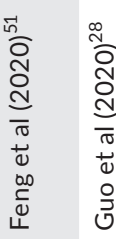

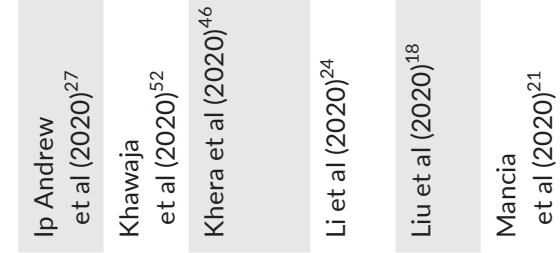



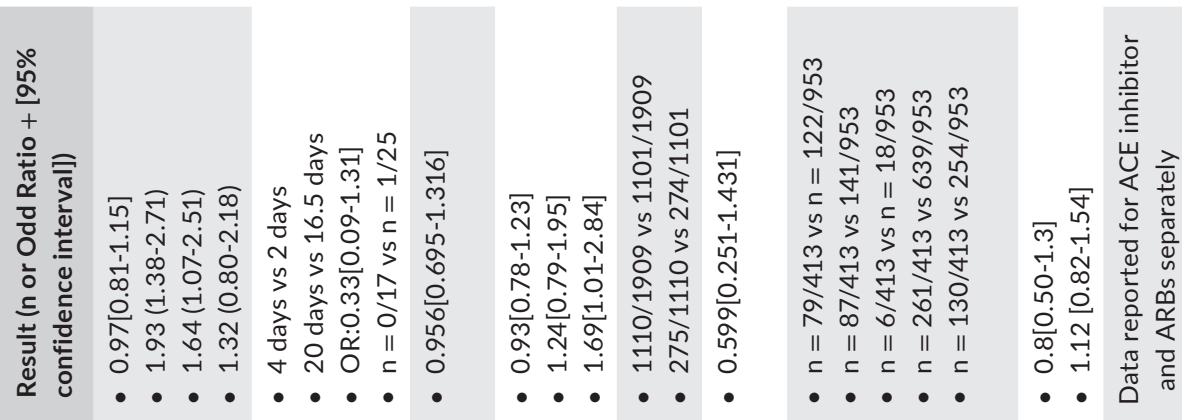

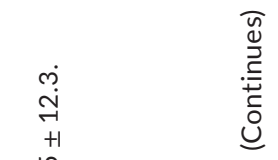
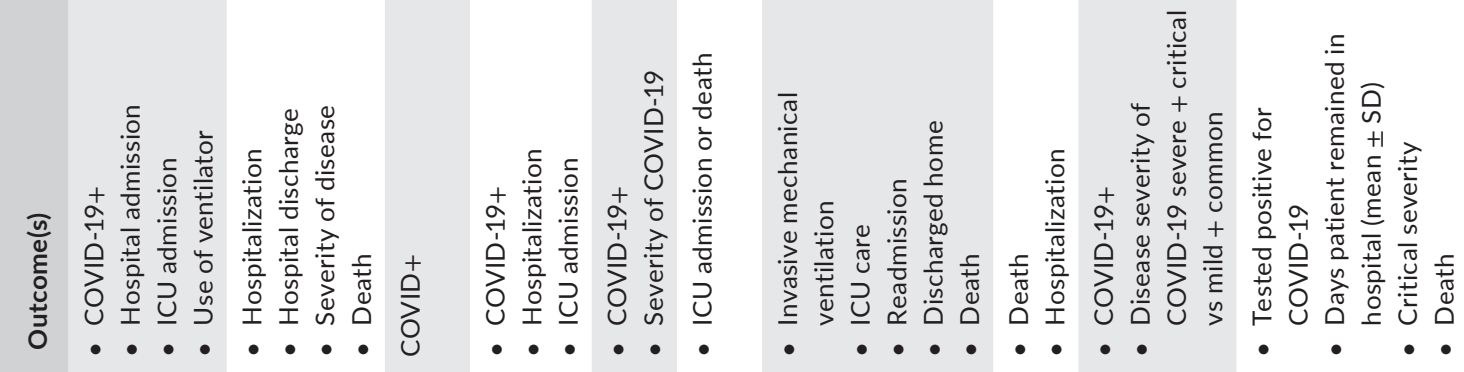

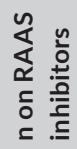

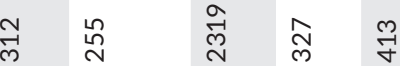

号 辛

ชุ

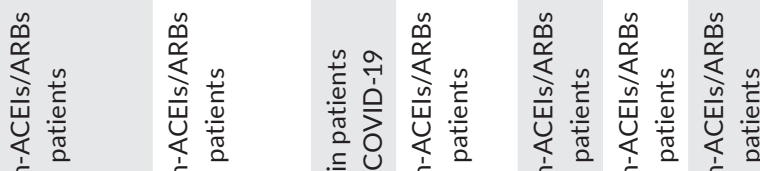

든

ठㅎำ

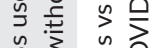

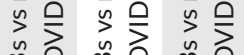

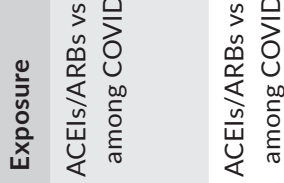

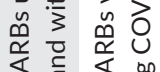

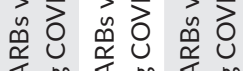

$\leqslant$ on

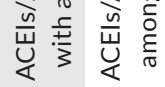

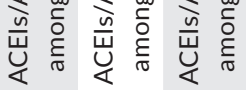

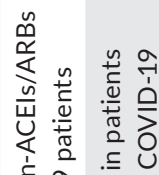

के के ज्ञ

它

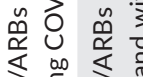

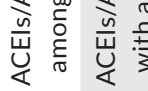

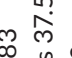

क ले

ป

$m+1 \geqslant$

I| थี ||

- •

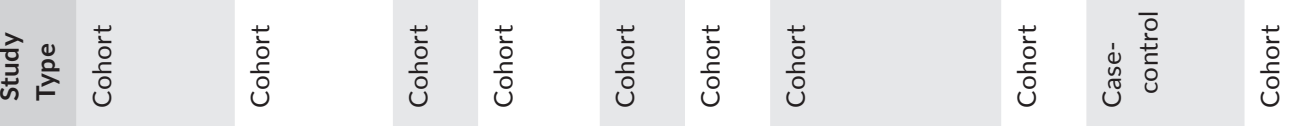

茝

尊

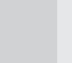

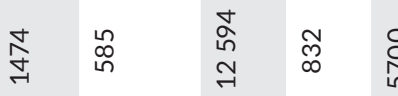

㞫

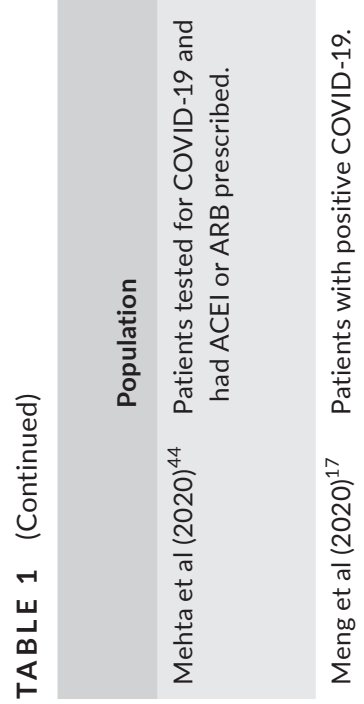

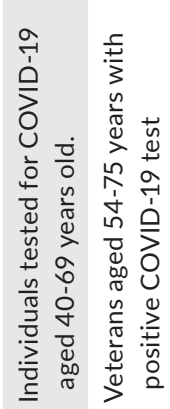
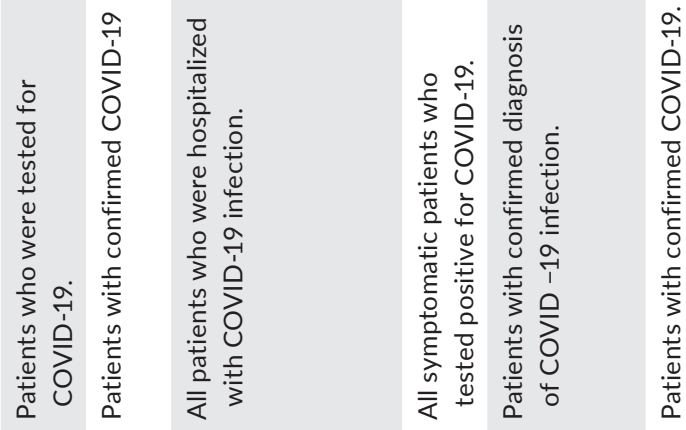

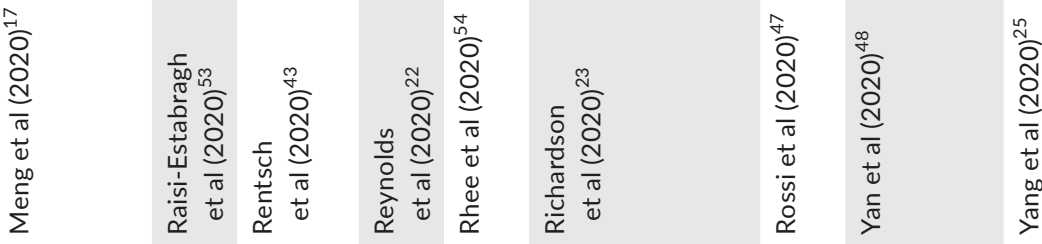




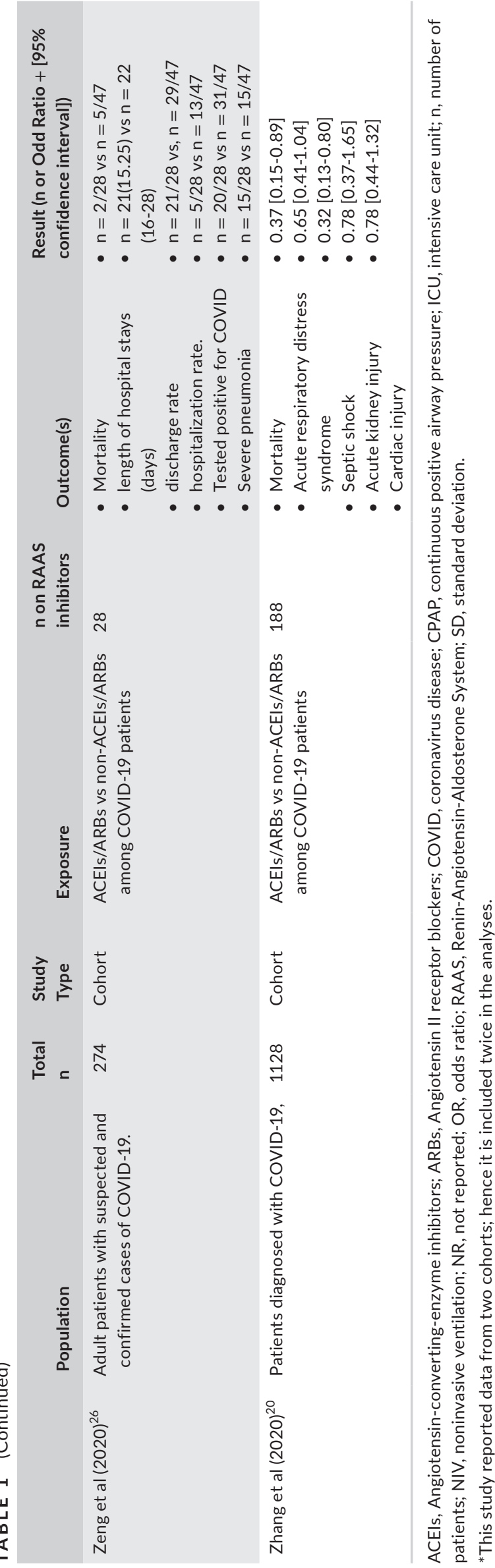

conflicting findings which is a concern given the controversies with hydroxychloroquine and lopinavir/ritonavir. For instance, some studies ${ }^{17-22}$ have reported a lower risk of severe COVID-19 outcomes with ACEIs/ ARBs while another study ${ }^{23}$ found a higher risk. Similarly, ACEIs/ARBs have been associated with lower mortality rates in some studies ${ }^{17,20,24-27}$ while others ${ }^{23,28}$ reported higher mortality rates. We are also aware that two recently published systematic reviews ${ }^{29,30}$ containing 16 studies reported no evidence of any association between ACEls/ARBs and mortality, severe COVID-19 outcomes, or acquiring COVID-19 infection; however, these studies only analyzed a limited range of outcomes, and did not report the effects of ACEls and ARBs individually. The authors also did not undertake any subgroup analysis to explore the effect of potential confounders such as the study's quality and there are concerns that the findings may now be out-dated. Furthermore, one of these studies ${ }^{30}$ only used narrative synthesis of the data. Consequently, we sought to undertake an updated and comprehensive evaluation of effect of ACEIs/ARBs use on all reported COVID-19-related outcomes, including exploration of any class differences, through a systematic review of the literature coupled with a meta-analysis.

\section{2 | METHODS}

\subsection{Data source and searches}

This systematic review and meta-analysis was conducted and reported in accordance to the Preferred Reporting Items for Systematic Reviews and Meta-Analyses (PRISMA) statement checklist. ${ }^{32}$ A protocol was drafted and shared with authors but not registered in any database as we did not want the submission of our findings to be delayed until the study protocol was registered as we wanted to provide the clinical community with a timely publication of the available evidence whether published in peer-reviewed journals or awaiting publication surrounding the impact of ACEIs/ARBs use on COVID-19 outcomes. The literature search was conducted in Embase, Medline (OVID), Scopus, Cochrane library, and medRxiv, from inception to 22 May 2020, using key terms related to ACEIs/ ARBs and COVID-19 concepts. A detailed electronic search strategy used in the database searches is attached [File S1]. We also manually searched the reference list of eligible articles to identify any further relevant articles.

\subsection{Study selection}

Eligibility criteria included original research studies, published in English, with COVID-19 patients (target population) that reported the effects of ACEls/ARBs (intervention), in comparison with non-ACEls/ ARBs use (comparison), on COVID-19-related outcomes. No restrictions were placed on the reported outcomes or study types. All records identified from the search strategy were exported from the databases and imported into Covidence ${ }^{\circledR 31}$ whereby duplicate records were removed. Two reviewers (NA and LA) independently undertook titles 


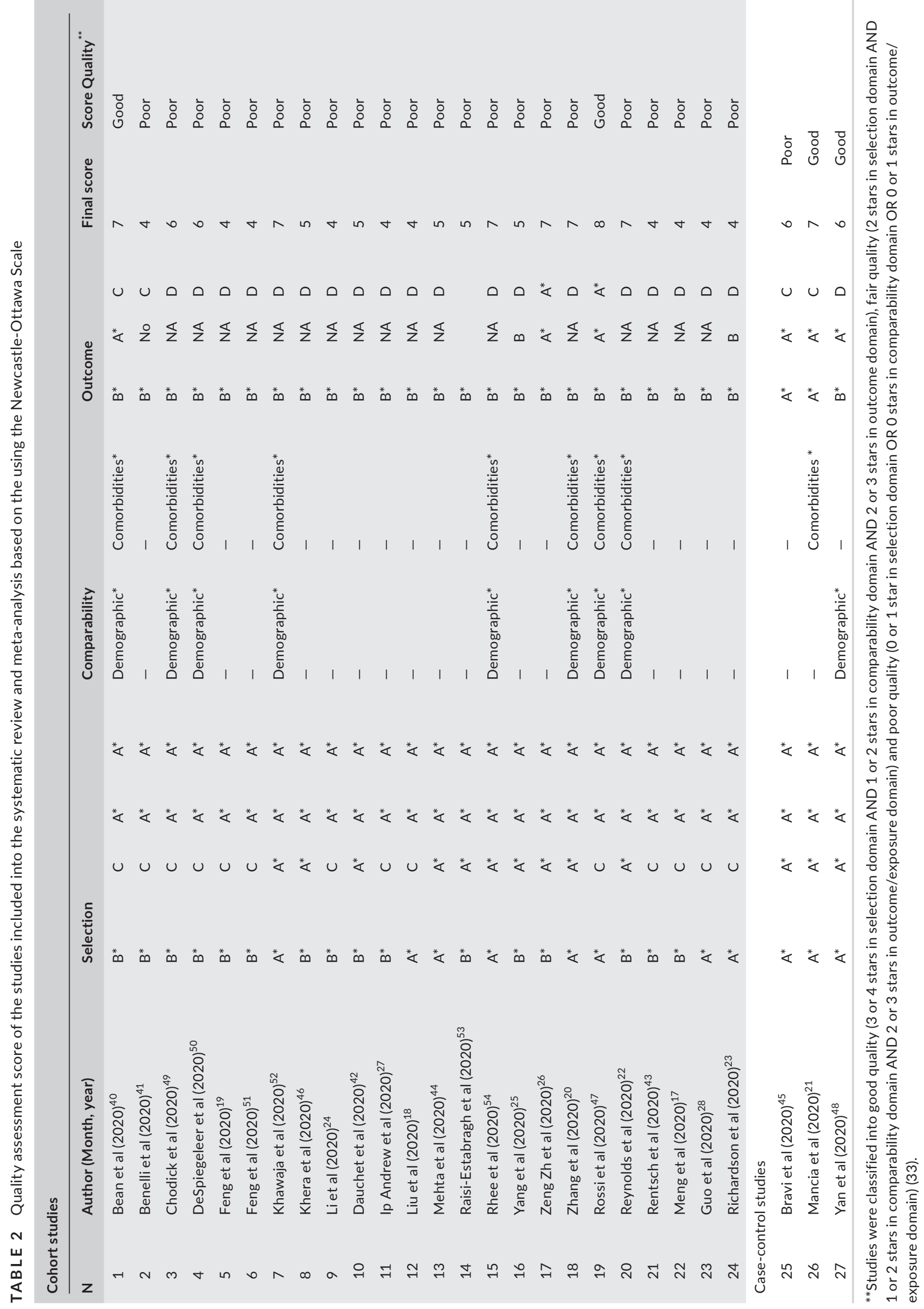


Study

ID
Death

\section{ACEIs/ARBs}

Bean et al., (May 2020)

Benelli et al., (April 2020)

Li et al., (April 2020)

Andrew Ip et al., (April 2020)

Yang et al., (May 2020)

Zeng et al., (April 2020)

Zhang, etal., (April 2020)

Rossi et al., (April 2020)

Meng el al., (March 2020)

Guo et al., (May 2020)

Richardson et al., (April 2020)

Subtotal $(\mathrm{I}$-squared $=65.5 \%, p=0.001$ )

ACEls

Benelli et al., (April 2020)

Khera et al.,

Subtotal $(\mathrm{I}$-squared $=26.3 \%, p=0.244$ )

ARBs

Benelli et al., (April 2020)

Khera et al.,

Subtotal ( -squared $=0.6 \%, p=0.316$ )

Overall (I-squared $=58.8 \%, p=0.002)$

NOTE: Weights are from random effects analysis

.00828

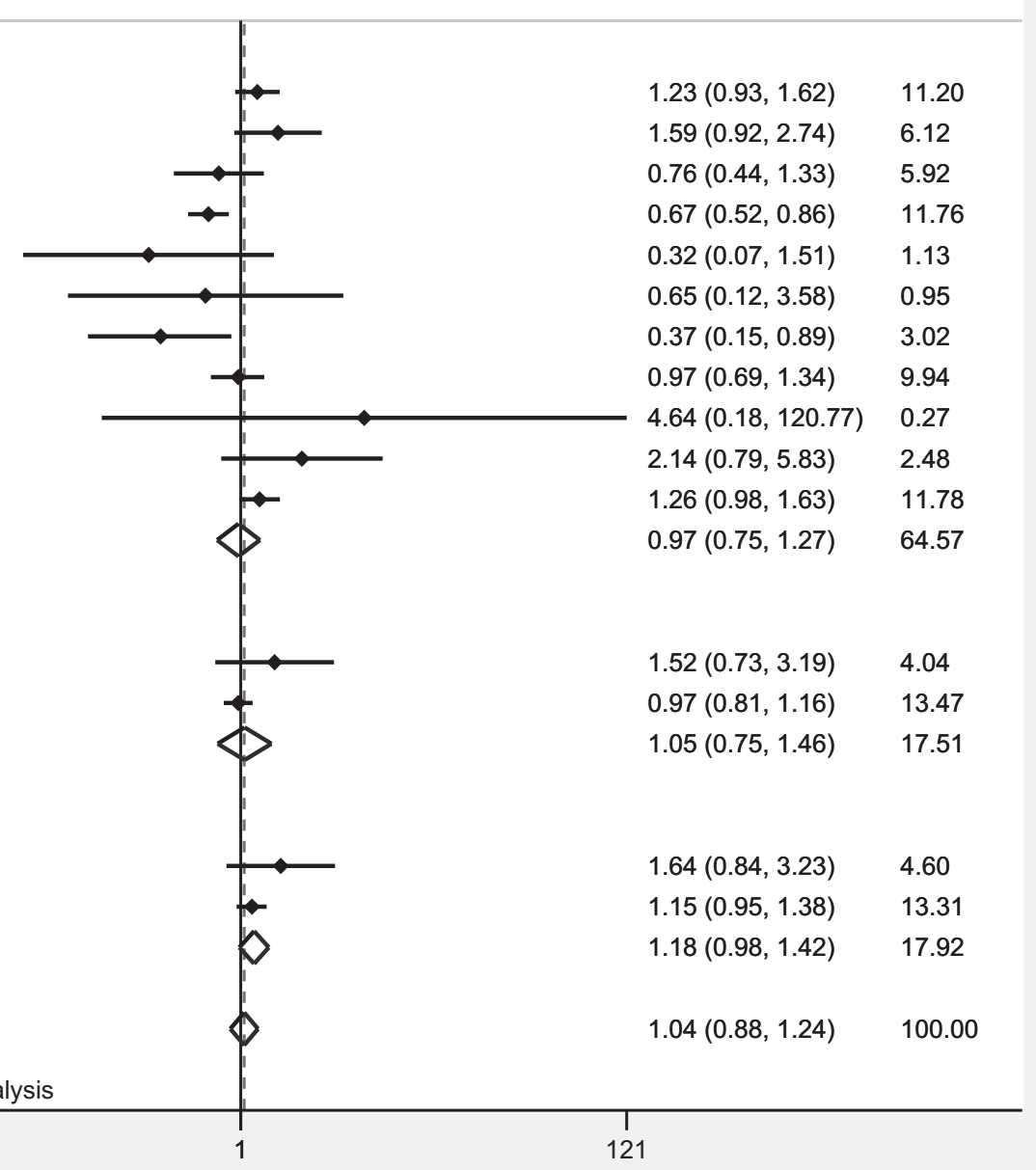

Odds ratio

$\begin{array}{ll}1.23(0.93,1.62) & 11.20 \\ 1.59(0.92,2.74) & 6.12 \\ 0.76(0.44,1.33) & 5.92 \\ 0.67(0.52,0.86) & 11.76 \\ 0.32(0.07,1.51) & 1.13 \\ 0.65(0.12,3.58) & 0.95 \\ 0.37(0.15,0.89) & 3.02 \\ 0.97(0.69,1.34) & 9.94 \\ 4.64(0.18,120.77) & 0.27 \\ 2.14(0.79,5.83) & 2.48 \\ 1.26(0.98,1.63) & 11.78 \\ 0.97(0.75,1.27) & 64.57\end{array}$

$1.52(0.73,3.19) \quad 4.04$

$0.97(0.81,1.16) \quad 13.47$

$1.05(0.75,1.46) \quad 17.51$

$1.64(0.84,3.23) \quad 4.60$

$1.15(0.95,1.38) \quad 13.31$

$1.18(0.98,1.42) \quad 17.92$

$1.04(0.88,1.24) \quad 100.00$
$\%$

ES $(95 \% \mathrm{Cl}) \quad$ Weight

FIGURE 2 Forest plot depicting pooled estimates for the association between mortality and the three levels of renin-angiotensin system drug exposure (ACEIs/ARBs, ACEIs, ARBs)

and abstract screening for relevance, followed by selecting records for full-text screening and data extraction. At each stage, discrepancies were resolved through discussion until consensus was achieved. A third author (AK) verified the eligibility of the included studies.

\subsection{Data extraction and quality assessment}

Data from the eligible studies were subsequently extracted by two authors (NA, AK) into a spreadsheet including information on the study characteristics (study design, setting, sample size, population, exposure-ACEls/ARBs, ACEls, or ARBs) and outcome measures including death, intensive care unit (ICU) admission, risk of COVID-19 infection, severe COVID-19 infection, severe pneumonia, hospitalization, hospital discharge, use of ventilators, duration of hospital stay, septic shock, acute kidney injury, cardiac injury, and hospital readmission. Since the need for using ventilators typically necessitates ICU admission, we combined studies that reported ICU admission and ventilator use as a further composite outcome measure. Two authors (NA and LA) independently conducted the assessment of risk of bias using the Newcastle-Ottawa Scale (NOS) for nonrandomized studies which consists of three domains (selection of participants and control (if applicable), comparability and exposure or outcome), ${ }^{32}$ whereby studies were classified into good quality ( 3 or 4 stars in selection domain AND 1 or 2 stars in comparability domain AND 2 or 3 stars in outcome domain), fair quality (2 stars in selection domain AND 1 or 2 stars in comparability domain AND 2 or 3 stars in outcome/exposure domain), and poor quality (0 or 1 star in selection domain OR 0 stars in comparability domain OR 0 or 1 stars in outcome/exposure domain) ${ }^{33}$; any disagreement between the two reviewers (NA and LA) 
TAB LE 3 Meta-analyses pooled estimates with $95 \% \mathrm{Cl}$ of the effects of ACEls/ARBs on COVID-19 related clinical outcomes

\begin{tabular}{|c|c|c|c|c|c|c|}
\hline Outcomes & ACEIs/ARBs & $P$-value & ACEls & $P$-value & ARBs & $P$-value \\
\hline Number of studies & 11 & & 2 & & 2 & \\
\hline ICU & $1.086(0.652,1.809)$ & 0.75 & $0.945(0.65,1.376)$ & 0.769 & $1.49(1.126,1.973)$ & 0.005 \\
\hline Number of studies & 6 & & 3 & & 3 & \\
\hline Death/ICU & $0.67(0.524,0.857)$ & 0.001 & $0.888(0.694,1.136)$ & 0.345 & $0.83(0.65,1.061)$ & 0.136 \\
\hline Number of studies & 3 & & 2 & & 2 & \\
\hline I-squared ( $P$-value) & $0 \%$ & 0.572 & $0 \%$ & 0.726 & $0 \%$ & 1.000 \\
\hline Risk of COVID-19 & $1.014(0.935,1.099)$ & 0.745 & $1.133(1.417,21.27)$ & 0.273 & $0.557(0.107,2.895)$ & 0.46 \\
\hline Number of studies & 6 & & 3 & & 3 & \\
\hline I-squared ( $P$-value) & $43.3 \%$ & 0.117 & $0 \%$ & 0.799 & $18 \%$ & 0.296 \\
\hline Severe pneumonia & $1.285(0.237,6.958)$ & 0.771 & NA & & NA & \\
\hline Number of studies & 2 & & & & & \\
\hline I-squared ( $P$-value) & $57.5 \%$ & 0.125 & & & & \\
\hline Hospitalization & $1.153(0.806,1.65)$ & 0.436 & $1.077(0.791,1.465)$ & 0.638 & $0.907(0.74,1.112)$ & 0.349 \\
\hline Number of studies & 5 & & 5 & & 5 & \\
\hline I-squared (P-value) & $74.5 \%$ & 0.003 & $63.7 \%$ & 0.026 & $0 \%$ & 0.965 \\
\hline Hospital discharge & $1.213(0.739,1.991)$ & 0.446 & NA & & NA & \\
\hline Number of studies & 10 & & 5 & & 5 & \\
\hline I-squared ( $P$-value) & $83.2 \%$ & $<0.001$ & $75.2 \%$ & 0.003 & $66.2 \%$ & $<0.001$ \\
\hline
\end{tabular}

Note: NA, not applicable indicating no enough studies to perform meta-analyses

was resolved by involving a third researcher (AK) for discussion until a consensus was reached. Furthermore, interrater reliability measures such as kappa statistic and percentage agreement were also calculated. Some of the coauthors have used this approach before. ${ }^{34}$

\section{4 | Data synthesis and analysis}

For each study outcome that was reported by more than one study, the results from individual studies were combined statistically using the random-effects meta-analysis model, stratified by the level of exposure (ACEIs/ARBs, ACEIs, ARBs); whereas for outcomes which were reported by only one study, narrative synthesis was used. For studies which did not report the summary statistics and measure of effects, we firstly used the reported primary statistics (number of patients with/without the outcomes in both exposed/unexposed group) to calculate the corresponding measure of effects (Odds ratios- OR) and their 95\% confidence interval $(95 \% \mathrm{Cl}),{ }^{35}$ and subsequently used these measure of effects in the random-effects meta-analysis; the random-effects model was used as it is considered the most appropriate model by most researchers since it allows the results to be generalizable to other populations as well as addresses the likely heterogeneity between the included studies. ${ }^{36}$ Several subgroup analyses were also undertaken to explore the effect of potential confounders on the robustness and sensitivity of combined pooled estimates and included subgroup analyses based on whether the reported measure of effects was crude or adjusted, whether the study was peerreviewed or not, the study's methodological quality as per the risk of bias assessment was performed as well as the continent where 
TAB LE 4 Subgroup meta-analyses pooled estimates with $95 \% \mathrm{Cl}$ of the effects of ACEls/ARBs on COVID-19 related clinical outcomes

\begin{tabular}{|c|c|c|c|}
\hline & \multicolumn{3}{|l|}{ Death $(n=15)$} \\
\hline Adjusted OR & $0.973(0.260,1.660)$ & NA & NA \\
\hline Crude OR & $1.048(0.772,1.424)$ & $1.049(0.751,1.464)^{*}$ & $1.181(0.983,1.418)^{*}$ \\
\hline Yes & $0.894(0.522,1.533)$ & NA & NA \\
\hline No & $1.004(0.716,1.408)$ & $1.049(0.751,1.464)^{*}$ & $1.181(0.983,1.418)^{*}$ \\
\hline Number of studies & 6 vs 5 & 0 vs 2 & 0 vs 2 \\
\hline \multicolumn{4}{|l|}{ Study's quality } \\
\hline \multicolumn{4}{|l|}{ Study's country } \\
\hline Europe & $1.176(0.932,1.483)$ & $1.523(0.728,3.185)$ & $1.645(0.838,3.229)$ \\
\hline USA & $0.92(0.494,1.714)$ & $0.97(0.811,1.161)$ & $1.15(0.954,1.386)$ \\
\hline Asia & $0.753(0.401,1.413)$ & NA & NA \\
\hline \multirow[t]{2}{*}{ Number of studies } & 3 vs 2 vs 6 & 1 vs 1 vs 0 & 1 vs 1 vs 0 \\
\hline & ICU admission $(n=12)$ & & \\
\hline
\end{tabular}

Adjusted outcome measure

\begin{tabular}{|c|c|c|c|}
\hline Adjusted OR & NA & NA & NA \\
\hline Crude OR & $1.086(0.652,1.809)^{*}$ & $0.945(0.650,1.376)^{*}$ & $1.490(1.126,1.973)^{*}$ \\
\hline Number of studies & 0 vs 6 & 0 vs 3 & 0 vs 3 \\
\hline \multicolumn{4}{|l|}{ Peer-reviewed article? } \\
\hline Yes & $1.560(1.234,1.972)$ & NA & NA \\
\hline No & $0.762(0.295,1.972)$ & $0.945(0.650,1.376)^{*}$ & $1.490(1.126,1.973)^{*}$ \\
\hline Number of studies & 3 vs 3 & 0 vs 3 & 0 vs 3 \\
\hline \multicolumn{4}{|l|}{ Study's quality } \\
\hline Good quality & $0.364(0.224,0.591)$ & NA & NA \\
\hline Poor quality & $1.445(0.133,1.843)$ & $0.945(0.650,1.376)^{*}$ & $1.490(1.126,1.973)^{*}$ \\
\hline Number of studies & 1 vs 5 & 0 vs 3 & 0 vs 3 \\
\hline \multicolumn{4}{|l|}{ Study's country } \\
\hline Europe & $0.495(0.253,0.966)$ & $0.945(0.650,1.376)^{*}$ & $1.490(1.126,1.973)^{*}$ \\
\hline USA & $1.591(1.277,1.983)$ & NA & NA \\
\hline Asia & $1.439(0.600,3.453)$ & NA & NA \\
\hline \multirow[t]{2}{*}{ Number of studies } & 2 vs 3 . vs 1 & 3 vs 0 . vs 0 & 3 vs 0. vs 0 \\
\hline & \multicolumn{3}{|c|}{ Death/ICU admission $(n=7)$} \\
\hline \multicolumn{4}{|c|}{ Adjusted outcome measure } \\
\hline Adjusted OR & $0.630(0.471,0.842)$ & NA & NA \\
\hline Crude OR & $0.783(0.493,1.243)$ & $0.888(0.694,1.136)^{*}$ & $0.830(0.650,1.061)$ \\
\hline Number of studies & 1 vs 2 & 0 vs 2 & 0 vs 2 \\
\hline \multicolumn{4}{|l|}{ Peer-reviewed article? } \\
\hline Yes & NA & $0.910(0.690,1.210)$ & $0.830(0.630,1.100)$ \\
\hline No & $0.670(0.524,0.857)^{*}$ & $0.820(0.490,1.360)$ & $0.830(0.500,1.400)$ \\
\hline Number of studies & 0 vs 3 & 1 vs 1 & 1 vs 1 \\
\hline
\end{tabular}


TABLE 4 (Continued)

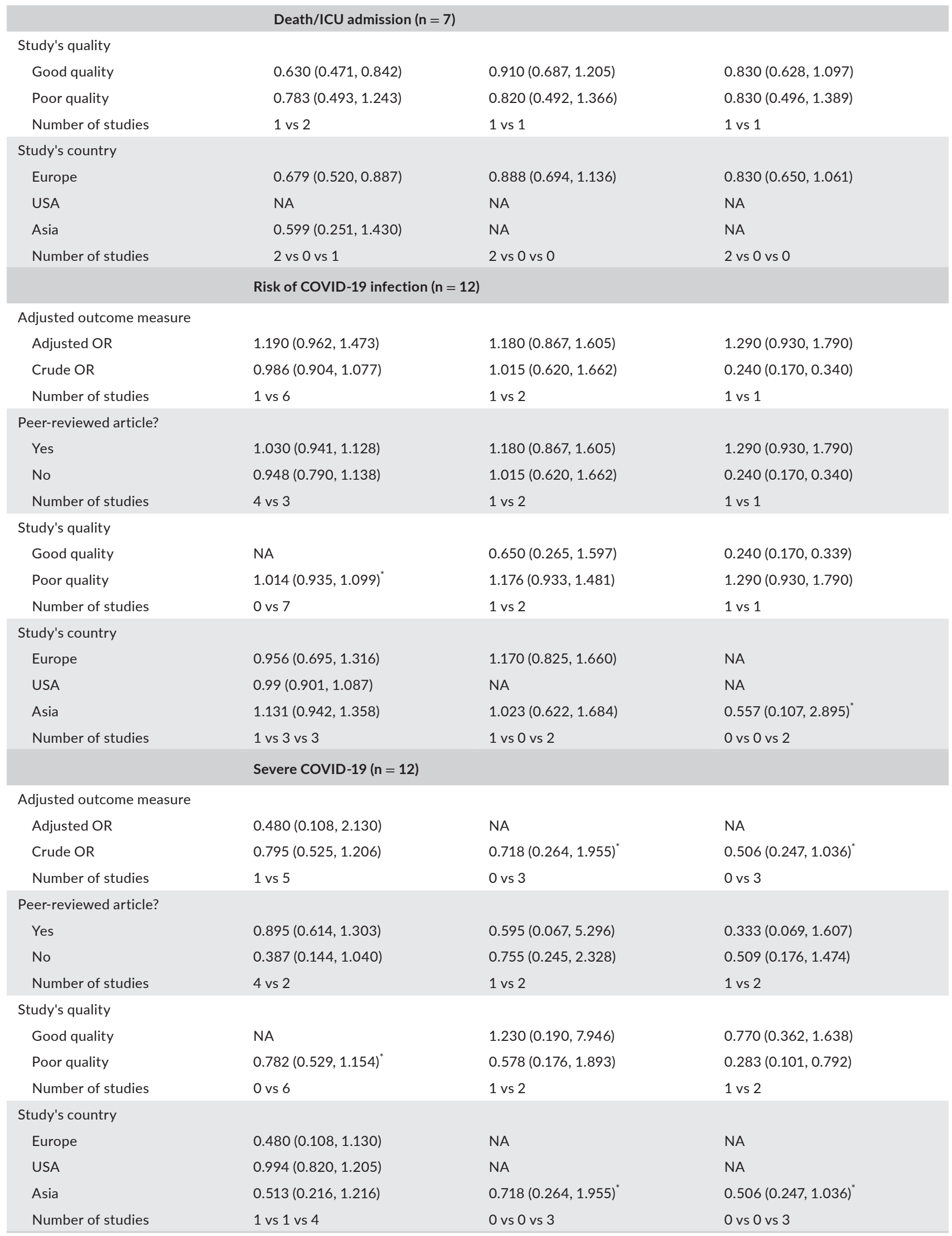


TABLE 4 (Continued)

Severe pneumonia $(n=2)$

Adjusted outcome measure

$\begin{array}{llll}\text { Adjusted OR } & 0.410(0.050,3.275) & \text { NA } & \text { NA } \\ \text { Crude OR } & 2.462(0.939,6.452) & \text { NA } & \text { NA } \\ \text { Number of studies } & 1 \text { vs } 1 & & \end{array}$

Peer-reviewed article?

$\begin{array}{llll}\text { Yes } & \text { NA } & \text { NA } & \text { NA } \\ \text { No } & 1.285(0.237,6.958) & \text { NA } & \text { NA } \\ \text { Number of studies } & 0 \text { vs } 2 & & \end{array}$

Study's quality

Good quality NA

Poor quality

NA

Number of studies
Study's country

$1.285(0.237,6.958)$

NA

NA

0 vs 2

$\begin{array}{llll}\text { Europe } & \text { NA } & \text { NA } & \text { NA } \\ \text { USA } & \text { NA } & \text { NA } & \text { NA } \\ \text { Asia } & 1.285(0.237,6.958) & & \\ \text { Number of studies } & 0 \text { vs } 0 \text { vs } 2 & & \end{array}$

Number of studies

0 vs 2

Hospitalization $(n=15)$

Adjusted outcome measure

\begin{tabular}{|c|c|c|c|}
\hline Adjusted OR & $1.300(1.113,1.518)$ & $1.170(0.900,1.520)$ & $1.0(0.702,1.424)$ \\
\hline Crude OR & $1.032(0.561,1.897)$ & $1.056(0.684,1.631)$ & $0.865(0.674,1.109)$ \\
\hline Number of studies & 1 vs 4 & 1 vs 4 & 1 vs 4 \\
\hline \multicolumn{4}{|l|}{ Peer-reviewed article? } \\
\hline Yes & $1.930(1.377,2.705)$ & NA & NA \\
\hline No & $0.977(0.647,1.474)$ & $1.077(0.791,1.465)^{*}$ & $0.907(0.740,1.112)^{*}$ \\
\hline Number of studies & 1 vs 4 & 0 vs 5 & 0 vs 5 \\
\hline \multicolumn{4}{|l|}{ Study's quality } \\
\hline Good quality & $1.300(1.113,1.518)$ & NA & NA \\
\hline Poor quality & $1.032(0.561,1.897)$ & $1.077(0.791,1.465)^{*}$ & $0.907(0.740,1.112)^{*}$ \\
\hline Number of studies & 1 vs 4 & 0 vs 5 & 0 vs 5 \\
\hline \multicolumn{4}{|l|}{ Study's country } \\
\hline Europe & $0.907(0.413,1.992)$ & $1.181(0.843,1.656)$ & $0.922(0.721,1.179)$ \\
\hline USA & $1.589(1.033,2.443)$ & $0.77(0.527,1.124)$ & $0.877(0.611,1.258)$ \\
\hline Asia & $0.569(0.178,1.815)$ & NA & NA \\
\hline \multirow[t]{2}{*}{ Number of studies } & 2 vs 2 vs 1 & 4 vs 1 vs 0 & 4 vs 1 vs 0 \\
\hline & \multicolumn{3}{|c|}{ Hospital discharge $(n=3)$} \\
\hline \multicolumn{4}{|c|}{ Adjusted outcome measure } \\
\hline Adjusted OR & NA & NA & NA \\
\hline Crude OR & $1.213(0.739,1.991)$ & NA & NA \\
\hline Number of studies & 0 vs 3 & & \\
\hline \multicolumn{4}{|l|}{ Peer-reviewed article? } \\
\hline Yes & $0.844(0.663,1.074)$ & NA & NA \\
\hline No & $1.513(1.184,1.935)$ & NA & NA \\
\hline Number of studies & 1 vs 2 & & \\
\hline
\end{tabular}

(Continues) 
TABLE 4 (Continued)

\begin{tabular}{|c|c|c|c|}
\hline & \multicolumn{3}{|c|}{ Hospital discharge $(n=3)$} \\
\hline Good quality & NA & NA & NA \\
\hline Poor quality & $1.213(0.739,1.991)$ & NA & NA \\
\hline Number of studies & 0 vs 3 & & \\
\hline \multicolumn{4}{|l|}{ Study's country } \\
\hline USA & $1.122(0.641,1.964)$ & NA & NA \\
\hline Asia & $1.862(0.659,5.26)$ & NA & NA \\
\hline \multirow[t]{2}{*}{ Number of studies } & 0 vs 2 vs 1 & & \\
\hline & Ventilator use $(n=8)$ & & \\
\hline Number of studies & 0 vs 4 & 0 vs 2 & 0 vs 2 \\
\hline \multicolumn{4}{|l|}{ Peer-reviewed article? } \\
\hline Yes & $1.141(0.606,2.150)$ & $0.078(0.001,6.878)$ & $0.251(0.053,1.185)$ \\
\hline No & $3.338(2.035,5.475)$ & $3.603(1.889,6.872)$ & $3.129(1.699,5.761)$ \\
\hline Number of studies & 1 vs 3 & 1 vs 1 & 1 vs 1 \\
\hline \multicolumn{4}{|l|}{ Study's quality } \\
\hline Good quality & NA & NA & NA \\
\hline Poor quality & $1.492(0.804,2.770)$ & $1.014(0.030,34.758)$ & $0.985(0.084,11.570)$ \\
\hline Number of studies & 0 vs 4 & 0 vs 2 & 0 vs 2 \\
\hline
\end{tabular}

${ }^{*}$ Indicates that the pooled estimate is the same as the overall analyses because all the studies were in one group; NA: not applicable indicating that no studies were available to perform meta-analyses for these outcomes;

the study was conducted. Meta-analyses pooled estimates were presented as odds ratios and $95 \% \mathrm{Cl}$ and graphically as forest plots. Heterogeneity between the studies was evaluated using $I^{2}$ statistic, ${ }^{37}$ indicating whether variability is more likely due to study heterogeneity or chance. Negative $I^{2}$ values were set to zero, hence $I^{2}$ values ranged between $0 \%$ and $100 \%$ with $0 \%$ indicating lack of heterogeneity, whereas $25 \%, 50 \%$, and $75 \%$ indicating low, moderate and high heterogeneity, respectively. ${ }^{37}$ Publication bias was assessed using funnel plots and Egger's asymmetry test ${ }^{38}$ for those outcomes where $>10$ studies were included in the analysis as recommended by Cochrane guidelines. ${ }^{39}$ Data were analyzed using STATA 12.

\subsection{Role of the funding source}

None.

\section{3 | RESULTS}

\section{1 | Study characteristics}

The literature search identified 452 articles. However, only 27 studies were eligible for inclusion (Figure 1). A total of 72372 patients were included in these 27 studies of which 10197 (14.1\%) patients were on ACEls or ARBs. The average age of the population in these studies was $61 \pm 9.6$ years and men represented $52.24 \%$ of them (Table 1). Twenty-one studies (77.8\%) focused on comparing COVID19-related outcomes between ACEI/ARB users vs nonusers among patients with COVID-19 while the remaining six studies (22.2\%) focused on comparing outcomes between ACEIs/ARBs users in patients with and without COVID-19 infection (Table 1). ACEIs/ARBs in the included studies were indicated for a wide range of chronic conditions such as hypertension, coronary artery diseases, heart failure, diabetes, or chronic kidney disease. 
Study

\section{ACEIs/ARBs}

Bean et al., (May 2020)

Benelli et al., (April 2020)

Mehta et al., (May 2020)

Yang et al., (May 2020)

Rentsch et al., (April 2020)

Richardson et al., (April 2020)

Subtotal $(\mathrm{I}$-squared $=84.4 \%, p=0.000)$

ACEls

Benelli et al., (April 2020)

Dauchet et al., (May 2020)

Dauchet et al., (May 2020)

Subtotal $(\mathrm{I}$-squared $=4.9 \%, p=0.349$ )

\section{ARBs}

Benelli et al., (April 2020)

Dauchet et al., (May 2020)

Dauchet et al., (May 2020)

Subtotal $(\mathrm{I}$-squared $=0.0 \%, p=0.475$ )

Overall $(\mathrm{I}$-squared $=72.2 \%, p=0.000)$

NOTE: Weights are from random effects analysis

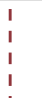

$\begin{array}{lcc}162 & 1 & 1 \\ & \text { Odds ratio } & 6.17\end{array}$

ICU admission

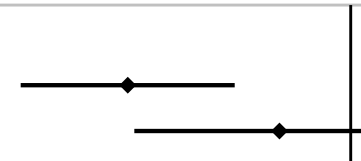

ES $(95 \% \mathrm{Cl})$

$\%$

Weight

FIGURE 3 Forest plot depicting pooled estimates for the association between Intensive Care Unit admission and the three levels of renin-angiotensin system drug exposure (ACEIs/ARBs, ACEIs, ARBs)

In terms of outcomes, nine studies (33.3\%) reported three to five COVID-19-related outcomes, ${ }^{20,23,25,26,40-44}$ while another nine studies (33.3\%) reported only two outcomes ${ }^{17,19,22,24,27,45-48}$ with another one-third reported only one outcome. ${ }^{19,22,29,46-51}$ Overall, the 27 studies reported data on 15 unique outcomes including death in 12 studies, ${ }^{18,21,28,49-54}$ ICU admission in seven studies, ${ }^{23,25,40-44}$ death/ICU admission as a composite outcome in four studies, ${ }^{21,40,45,54}$ risk of acquiring COVID-19 infection in nine studies, ${ }^{22,25,26,42-44,48,49,53}$ risk of severe COVID-19 infection in seven studies, ${ }^{17-19,22,24,48,50}$ risk of severe pneumonia in two studies, ${ }^{26,51}$ risk of hospitalization in eight studies, ${ }^{26,42-47,52}$ hospital discharge in three studies, ${ }^{23,26,27}$ use of ventilator in four studies, ${ }^{19,23,41,44}$ duration of hospital stay in two studies, ${ }^{25,26}$ and each of acute respiratory distress syndrome (ARDS), septic shock, cardiac shock, acute kidney injury, ${ }^{20}$ and hospital readmission ${ }^{23}$ in one study, respectively. In terms of the exposure, the effects of ACEls and ARBs were assessed as one class (ACEls/ARBs) in 17 studies (63\%), ${ }^{17,20,22-28,40,43,44,47,50,51,53,54}$ as separate classes in five studies (18.5\%) 52, 74, 78, 80, 84), and both as one and separate classes in another five studies. ${ }^{18,19,41,45,49}$

The majority of the 27 eligible studies were conducted in Asia (44.4\%, $\mathrm{n}=12$ with 10 studies from China, one each from Korea and Israel), followed by nine studies (33.3\%) from Europe (four in Italy, three in the United Kingdom and one each from France and Belgium) and the remaining six (22.3\%) from the USA. Furthermore, the reported measure of effects were crude/unadjusted measures in the majority of the studies $(77.8 \%, n=21)^{18,19,21-28,40-46,48,53,54}$; with most of them (59.3\%, $\mathrm{n}=16$ ) being nonpeer-reviewed articles published as preprints on medRivix, ${ }^{24,26,27,40-43,45-48,50-54}$ and only four rated as a good quality studies based on the Newcastle-Ottawa Quality Assessment risk of bias ${ }^{21,40,47,48}$ (Table 2). Results from the interrater reliability measures indicated a substantial agreement between the 
Study

ID ACEIs/ARBs

Bean et al., (May 2020)

Bravi et al., (May 2020)

Rhee et al., (May 2020)

Subtotal (I-squared $=0.0 \%, p=0.572$ )

ACEls

Bravi et al., (May 2020)

Mancia et al., (May 2020)

Subtotal (I-squared $=0.0 \%, p=0.726$ )

\section{ARBs}

Bravi et al., (May 2020)

Mancia et al., (May 2020)

Subtotal $($ I-squared $=0.0 \%, p=1.000$ )

Overall (I-squared $=0.0 \%, p=0.678$ )

NOTE: Weights are from random effects analysis

.251

Death or ICU admission

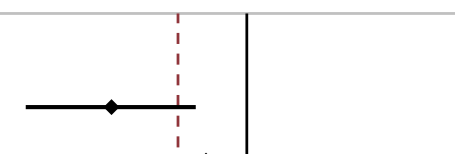

$\%$

ES $(95 \% \mathrm{Cl}) \quad$ Weight

$\begin{array}{ll}0.63(0.47,0.84) & 23.87 \\ 0.87(0.50,1.49) & 6.75 \\ 0.60(0.25,1.43) & 2.66 \\ 0.67(0.52,0.86) & 33.27\end{array}$

$0.82(0.49,1.36) \quad 7.72$

$0.91(0.69,1.21) \quad 25.51$

$0.89(0.69,1.14) \quad 33.23$

$0.83(0.50,1.40) \quad 7.59$

$0.83(0.63,1.10) \quad 25.91$

$0.83(0.65,1.06) \quad 33.50$

$0.79(0.69,0.91) \quad 100.00$

FIGURE 4 Forest plot depicting pooled estimates for the association between the composite outcome of mortality/ Intensive Care admission and the three levels of renin-angiotensin system drug exposure (ACEls/ARBs, ACEls, ARBs)

two independent reviewers (NA and LA) in assessing the risk of bias (kappa statistic $=0.79$; percentage of agreement $=89 \%(24 / 27)$ ).

\section{2 | Study outcomes}

\subsection{1 | Death and ICU admission}

Among pertinent studies, there was insignificant association between mortality and ACEIs/ARBs (OR: $0.97 ; 95 \% \mathrm{Cl}: 0.75$ 1.27), ACEls (OR:1.05; 95\% Cl: $0.75,1.46$ ), or ARBs (OR:1.18, $95 \% \mathrm{Cl}: 0.98,1.42$ ) (Figure 2; Table 3), regardless of the studies' country, quality, peer-review status or crude/adjusted measure of effect (File S2; Table 4). Similarly, there was an insignificant association between ICU admission and ACEIs/ARBs (OR: 1.09; 95\%: 0.65, 1.81) and ACEIs (OR:0.95; 95\% Cl: 0.65, 1.38) but significantly higher odds of ICU admission with ARBs (OR:1.49, 95\% Cl: 1.13, 1.97) (Figure 3; Table 3). However, subgroup analyses indicated different results. A significantly lower
ICU admission rate was associated with ACEIs/ARBs among European studies (OR:0.49; $95 \% \mathrm{Cl}: 0.25,0.97$ ), and good quality studies (OR:0.36; $95 \% \mathrm{Cl}: 0.22,0.59$ ), in contrast to significantly higher ICU admission rate among USA studies (OR:1.59; $95 \% \mathrm{Cl}: 1.28,1.98)$, peer-reviewed studies (OR:1.56; $95 \% \mathrm{Cl}$ : $1.23,1.97$ ), and poor quality studies (OR:1.44; $95 \% \mathrm{Cl}: 1.13$, 1.84) (File S3; Table 4). Meta-analysis of the three studies that reported death and ICU admission as a composite endpoint indicated significantly lower odds of death/ICU admission with ACEIs/ARBs use (OR:0.67; 95\% CI: 0.52, 0.86) but insignificant lower association with ACEIs (OR:0.89; $95 \% \mathrm{Cl}: 0.69,1.14)$ or ARBs (OR: $0.83 ; 95 \% \mathrm{Cl}: 0.65,1.06)$, regardless of any subgroup analysis for ACEls and ARBs (Figure 4; Table 3). The subgroup analyses for ACEls/ARBs, however, showed a significantly lower association of death/ICU admission with ACEls/ARBs only among European studies (OR: 0.68; 95\% Cl: 0.52, 0.89), good quality studies (OR:0.63; 95\% Cl: 0.47, 0.84), and studies which reported adjusted measure of effect (OR:0.63; $95 \% \mathrm{Cl}$ : 0.47, 0.84) (File S4; Table 4). 
Study

ID
Risk of COVID-19 infection

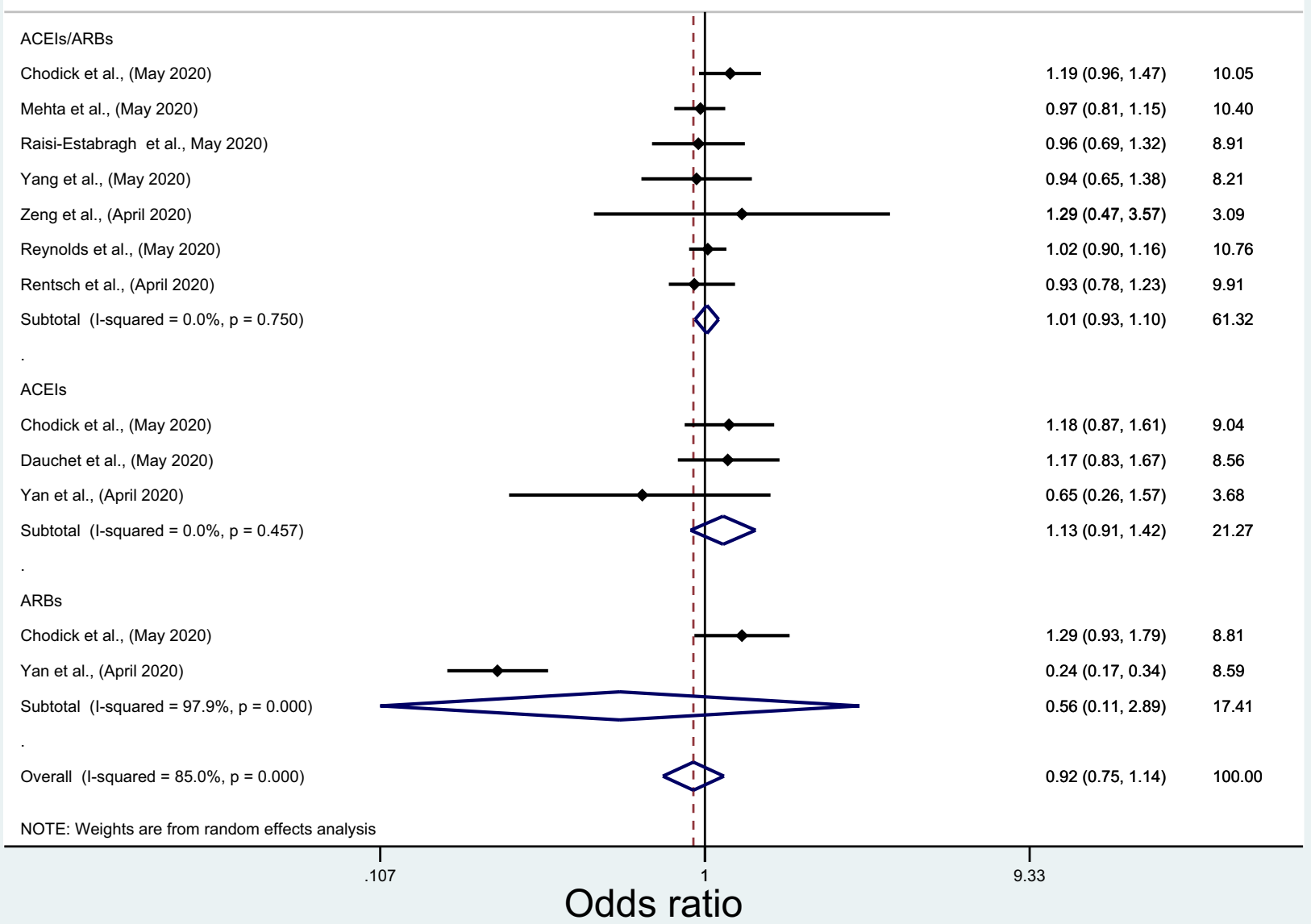

FIGURE 5 Forest plot depicting pooled estimates for the association between risk of acquiring COVID-19 infection and the three levels of renin-angiotensin system drug exposure (ACEIs/ARBs, ACEIs, ARBs)

\subsection{2 | Risk of acquiring COVID-19 infection, severe COVID-19 infection and severe pneumonia}

The overall pooled analysis of nine studies indicated insignificant association between the risk of acquiring COVID-19 infection and the use of ACEIs/ARBs (OR: 1.01; 95\% Cl: 0.93, 1.10), ACEIs (OR: 1.13; 95\% Cl: 0.9, 1.42), or ARBs (OR: 0.56; 95\% Cl: 0.11, 2.89) (Figure 5; Table 3). The subgroup analyses results were consistent with overall analyses results for ACEIs/ARBs and ACEIs (File S5A and B; Table 4) but they were inconsistent for ARBs with a significantly lower risk of acquiring COVID-19 with ARBs among nonpeer-reviewed studies, good-quality studies and studies which reported crude measure of effects (OR: 0.24; 95\% Cl: 0.17, 0.34) (File S5C; Table 4). Similarly, in a pooled analysis of seven and two studies, insignificant association was observed between the risk of developing severe COVID-19 infection, severe pneumonia, respectively, and ACEIs/ARBs (OR:0.78; 95\% Cl: 0.53, 1.15; OR:1.29; 95\%Cl: 0.24, 6.96), ACEls (OR: 0.72; 95\%Cl: 0.26, 1.95) or ARBs (OR: 0.51; 95\% Cl: 0.25, 1.04) (Figure 6; Table 3), regardless of any subgroup analysis (File S6; Table 4).

\subsection{3 | Hospitalization, hospital discharge and duration of hospital stay}

In a pooled analysis of eight and three studies, there was no signification association between hospitalization, hospital discharge rate and ACEls/ARBs (OR: 1.15; 95\%Cl: 0.81, 1.65; OR: 1.21; 95\%Cl: 0.74, 1.99), ACEls (OR: 1.08 ; $95 \% \mathrm{Cl}: 0.79,1.46)$ or ARBs (OR: $0.91 ; 95 \% \mathrm{Cl}: 0.74$, 1.11) (Figure 7; Figure 8 and Table 3). However, subgroup analyses demonstrated a significantly higher risk of hospitalization with ACEls/ARBs among studies conducted in the USA (OR:1.59; $95 \% \mathrm{Cl}: 1.03,2.44$ ), peer-reviewed studies (OR:1.93, 95\% Cl: 1.38, 2.71), good quality studies and studies which reported adjusted measure of effect (OR:1.30, 95\%Cl: 1.10, 1.50) (File S7; Table 4). Contrastingly, a significantly higher rate of hospital discharge was observed with ACEls/ARBs but only 
Study

ID
Severe COVID-19

\section{ACEIs/ARBs}

DeSpiegeleer et al., (May 2020)

Feng et al., (April 2020)

Li et al., (April 2020)

Liu et al., (March 2020)

Reynolds et al., (May 2020)

Meng el al., (March 2020)

Subtotal $(\mathrm{I}$-squared $=43.3 \%, p=0.117$ )

\section{ACEls}

Feng et al., (April 2020)

Liu et al., (March 2020)

Yan et al., (April 2020)

Subtotal (I-squared $=0.0 \%, p=0.799$ )

\section{ARBs}

Feng et al., (April 2020)

Liu et al., (March 2020)

Yan et al., (April 2020)

Subtotal $($ I-squared $=18.0 \%, p=0.296$ )

Overall (I-squared $=26.4 \%, p=0.185$ )

NOTE: Weights are from random effects analysis

$$
.056
$$
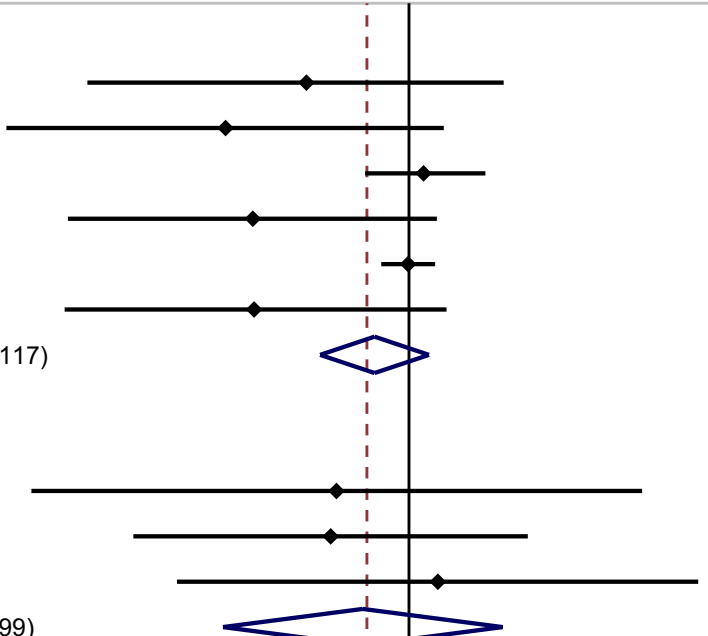

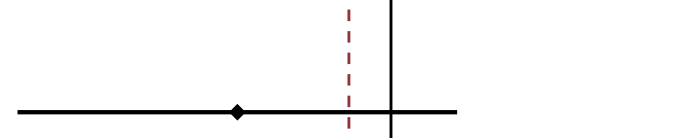

$$
\begin{array}{ll}
0.33(0.07,1.61) & 3.32 \\
0.25(0.06,0.98) & 4.31 \\
0.77(0.36,1.63) & 11.33 \\
0.51(0.25,1.04) & 18.96
\end{array}
$$

$0.74(0.55,1.00) \quad 100.00$

$\begin{array}{ll}0.60(0.07,5.31) & 1.79 \\ 0.57(0.14,2.34) & 4.04 \\ 1.23(0.19,7.93) & 2.42 \\ 0.72(0.26,1.95) & 8.25\end{array}$

FIGURE 6 Forest plot depicting pooled estimates for the association between developing severe COVID-19 infection and the three levels of renin-angiotensin system drug exposure (ACEIs/ARBs, ACEls, ARBs)

among nonpeer-reviewed articles (OR:1.51; 95\%Cl: 1.18, 1.93) (File S8; Table 4). Two studies reported data on the duration of hospital stay. Both were in favor of ACEls/ARBs with Yang et $a^{25}$ reporting a significant reduction in the mean duration of hospital stay of 2.3 days $(95 \% \mathrm{Cl}$ : -3.61, -0.99) with ACEIs/ARBs while Zeng et $a^{26}$ reported a lower median duration of hospital stay of 21 days (IRQ: 15-25) with ACEls/ARBs versus 22 days (IQR: 16-28) with non-ACEI/ARB use.

\subsubsection{Use of a ventilator}

Among pertinent studies, there was no significant association between these outcomes and the use of ACEls/ARBs (OR:1.49; 95\%Cl: 0.80, 2.77; OR: 1.26; 95\%Cl: 0.84, 1.80), ACEls (OR:1.01; 95\%Cl:0.03, 34.76; OR:1.15; 95\%: 0.55, 2.38), or ARBs (OR:0.98; 95\%Cl: 0.08, 11.57; OR: 1.48; 95\% Cl: 0.91, 2.38) (Figures 9 and 10; Table 3). However, significantly higher odds of ventilator use with
ACEIs/ARBs among the European studies (OR: 3.34; 95\%Cl: 2.04 , 5.48) and the USA (OR:1.52; $95 \% \mathrm{Cl}: 1.17,1.98)$ in contrast to significantly lower odds among those from Asia (OR:0.2; 95\% Cl: 0.04, 0.95) (File S9, Table 4). Contrastingly, significantly higher odds of ventilator use with ACEIs/ARBs was only observed among nonpeerreviewed studies (OR:3.34; 95\% Cl: 2.04, 5.48) (File S9, Table 1).

\subsection{5 | Other miscellaneous outcomes}

Zhang et $\mathrm{al}^{21}$ reported a significantly lower rate of septic shock (HR: $0.32 ; 95 \% \mathrm{Cl}: 0.13,0.8$ ) as well as nonsignificant lower rate of ARDS (HR: 0.65; 95\% Cl: 0.41, 1.04), acute kidney injury (HR:0.78; $95 \% \mathrm{Cl}: 0.37,1.65)$, and cardiac injury (HR: $0.76 ; 95 \% \mathrm{Cl}: 0.44$, 1.32) among ACEI/ARB users. Furthermore, Richardson et al, ${ }^{24}$ reported lower odds of hospital readmission with ACEIs/ARBs (OR: 0.77; 95\% Cl: 0.30, 1.94), albeit nonsignificant. 
Study

ID
$\%$
ES $(95 \% \mathrm{Cl}) \quad$ Weight

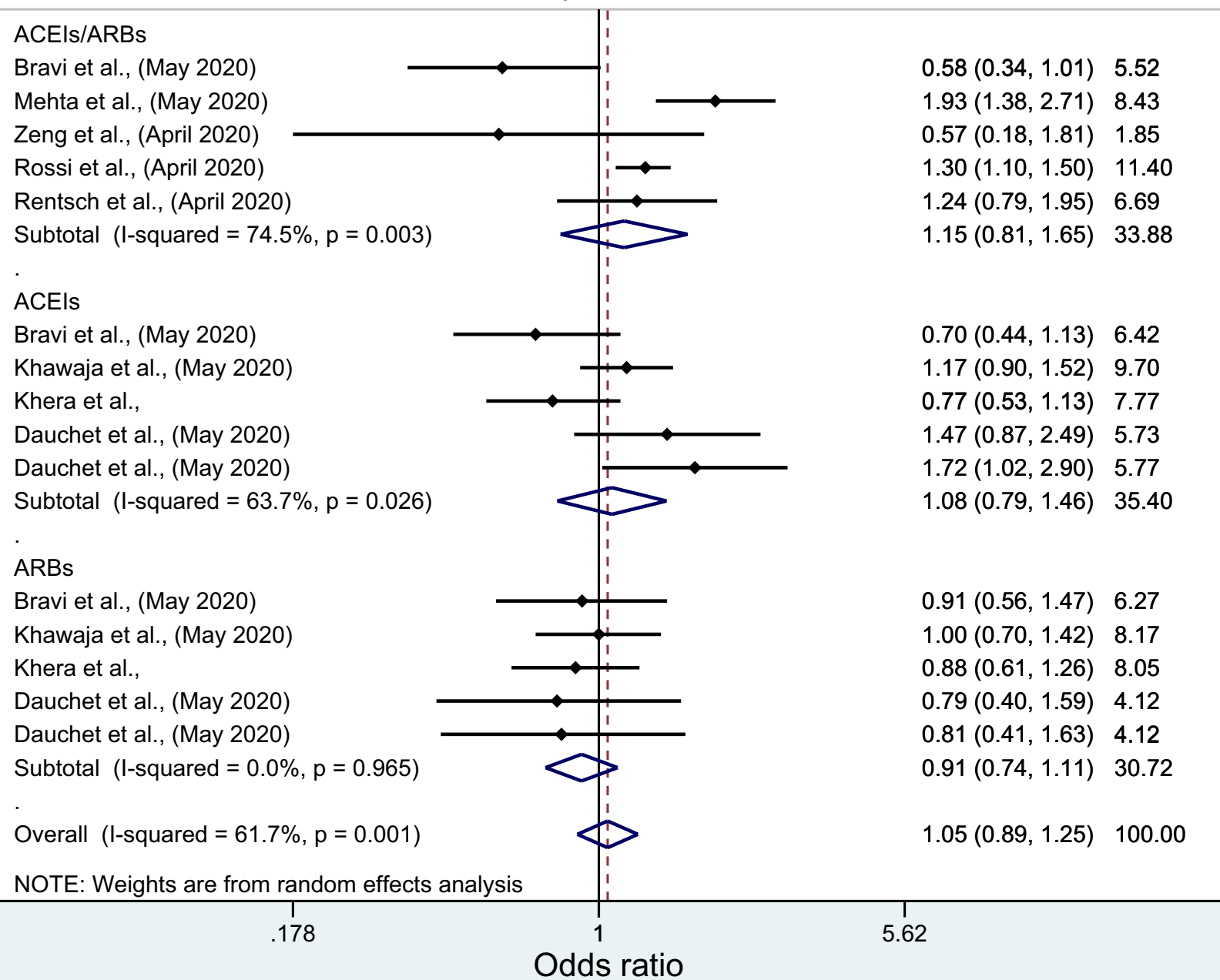

FIGURE 7 Forest plot depicting pooled estimates for the association between hospitalization and the three levels of renin-angiotensin system drug exposure (ACEls/ARBs, ACEls, ARBs)

\section{3 | Publication bias}

Results from the funnel plot (File S10) and Egger's asymmetry test for the death outcome, which was the only outcome whereby $>10$ studies were included in the meta-analysis, indicated statistically insignificant evidence of publication bias (bias coefficient: $0.85,95 \% \mathrm{Cl}$ : $-2.23,3.93, P=.445)$.

\section{4 | DISCUSSION}

The pooled analyses in this updated systematic review and meta-analysis indicated no evidence of any significant association between ACEIs/ ARBs and any COVID-19 related clinical outcomes; however, the subgroup analyses revealed evidence of a negative impact of ACEIs/ARBs use and some COVID-19-related clinical outcomes such as higher odds of hospitalization, ICU admission and ventilator use. Contrastingly, a positive impact were observed in terms of lower odds of death/ICU admission, as a composite outcome, and a higher rate of hospital discharge. Furthermore, our study findings, for the first time, showed interclass variations between ACEls and ARBs effects on COVID-19 clinical outcomes with low-quality evidence indicating lower risk of acquiring COVID-19, less severe COVID-19 infection, higher rate of ICU admission and ventilator use with ARBs but not ACEls.

Our study findings also showed no significant association between ACEIs/ARBs and mortality, severe COVID-19 infection, or positive tests for COVID-19, in agreement with two previously published systematic reviews. ${ }^{29,30}$ This was despite the inclusion of more recently published studies, ${ }^{18,27,40,41,49,50,53}$ which implies consistency of evidence. This is encouraging given the controversies 
ID

Severe Pnemonia (ACEIs/ARBs)

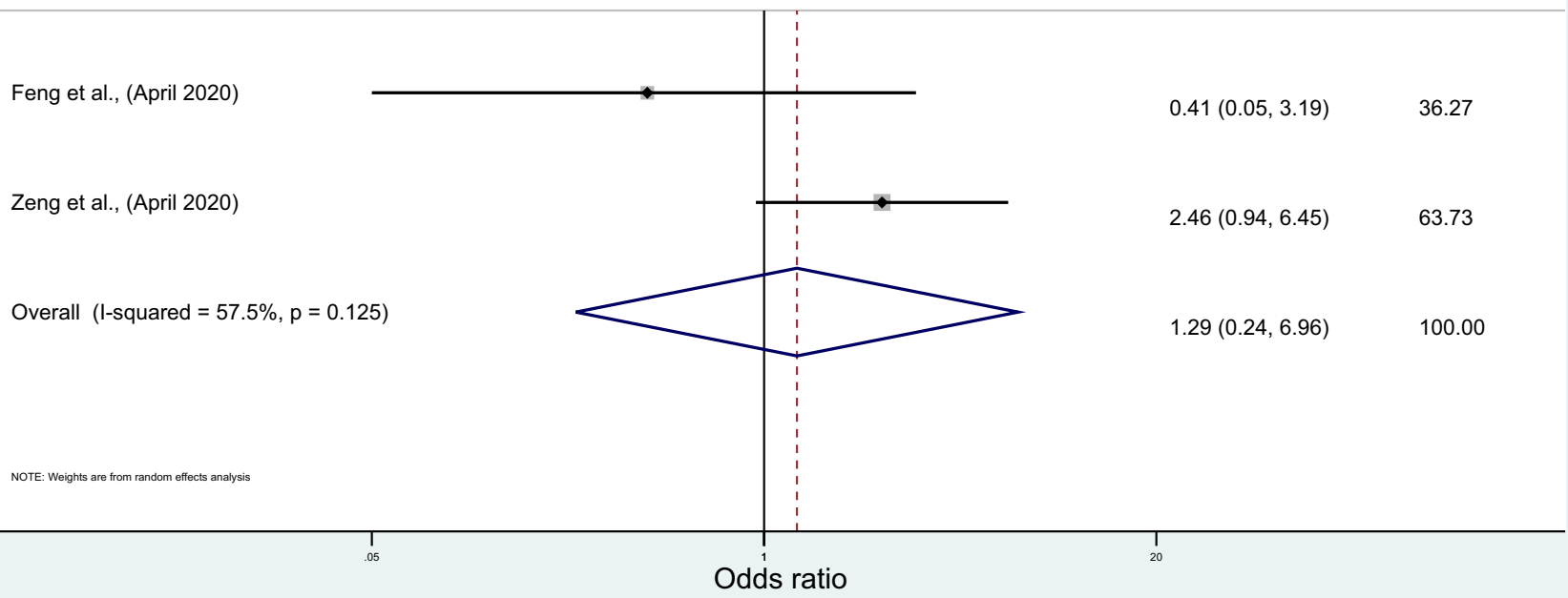

FIGURE 8 Forest plot depicting pooled estimate for the association between hospital discharge and ACEls/ARBs use

surrounding hydroxychloroquine. Furthermore, these nonsignificant associations were also observed for additional COVID-19related outcomes including ICU admission, hospitalization, and hospital discharge. However, unlike the previous two systematic reviews, ${ }^{29,30}$ our study found evidence of associations between ACEI/ARB use and certain COVID-19 clinical outcomes. While the pooled estimate of the subgroup analyses indicated a higher odds of ICU admission with ACEIs/ARBs among studies conducted in the USA ${ }^{23,43,44}$ and peer-reviewed studies, ${ }^{23,25,44}$ all these studies were of poor quality and none performed adjusted analyses to account for potential confounders. Confounding by indication is of particular concern with comorbidities such as CVD and diabetes associated with more severe COVID-19 morbidity and mortality. ${ }^{4-6}$ Similarly, the observed significant associations between ACEIs/ ARBs use and high odds of ventilator use and hospital discharge rates were from Benelli et $\mathrm{al}^{41}$ and $\mathrm{Ip}$ et $\mathrm{al}^{27}$ and Zeng et $\mathrm{al}^{26}$ respectively, all of which were nonpeer-reviewed, of poor quality and used crude analyses. Similarly, the studies in the pooled analyses that showed significant association of ARBs use and ICU admission, ${ }^{41,42}$ lower risk of acquiring COVID-19 infection, ${ }^{48}$ and severe infection ${ }^{18,19}$ were of poor quality, used unadjusted/crude analyses, and/or nonpeer-reviewed. In terms of duration of hospital stay, Yang et $\mathrm{al}^{25}$ and Zeng et $\mathrm{al}^{26}$ both reported a reduction in hospital stay with ACEIs/ARBs; however, it was not possible to combine them in the meta-analysis as they used a different measure of effects with the former reporting the outcome as a mean difference with the latter as a median.

On the other hand, our study findings showed some high-quality evidence on the association of ACEls/ARBs and higher odds of hospitalization but lower odds of death/ICU admission (as a composite endpoint). A higher odd of hospitalization was observed in the subgroup analyses of studies conducted in the USA ${ }^{43,44}$ although it should be noted that there was some heterogeneity $(57.7 \%)$ between the USA studies, used adjusted analyses, ${ }^{47}$ peer-reviewed ${ }^{44}$ and of good quality ${ }^{47}$; whereas the studies for lower death/ICU admission were from Europe, ${ }^{40,45}$ used adjusted analyses and of good quality, ${ }^{40}$ although none of them were peer-reviewed.

Several hypotheses have been suggested to explain the negative and positive effects of ACEIs/ARBs use on COVID-19 clinical outcomes. The former is thought to be related to ACEls/ARBs potential ability to upregulate ACE2, the cell entry point for COVID-19; hence facilitate COVID-19 cell entry and its subsequent infectivity/pathogenicity ${ }^{55}$; however, the evidence to date demonstrates ACE2's upregulation consistently in cardiac and renal tissues in response to ARBs therapy but not $\mathrm{ACEls}^{4,56}$; this observed difference between $A R B s$ and $A C E l s$ has been suggested to be due to the increased level of angiotensin II, which occurs following ARBs treatment but not ACEls, which in turn imposes an increased substrate load on ACE2 enzyme requiring its upregulation. ${ }^{57}$ Importantly, it should be emphasised that evidence of ACEIs/ARBs induced ACE2 upregulation 
Study

ID
ES $(95 \% \mathrm{Cl})$

Weight

\begin{tabular}{|c|c|c|c|}
\hline ACEIs/ARBs & 1 & & \\
\hline Benelli et al., (April 2020) & $1 \rightarrow$ & $3.34(2.04,5.47)$ & 17.11 \\
\hline Feng et al., (April 2020) & 1 & $0.20(0.04,0.95)$ & 7.24 \\
\hline Mehta et al., (May 2020) & 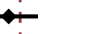 & $1.32(0.80,2.18)$ & 17.04 \\
\hline Richardson et al., (April 2020) & $\rightarrow$ & $1.61(1.18,2.20)$ & 18.89 \\
\hline Subtotal $(I-$ squared $=80.7 \%, p=0.001)$ & & $1.49(0.80,2.77)$ & 60.28 \\
\hline & $\mathrm{I}$ & & \\
\hline ACEls & 1 & & \\
\hline Benelli et al., (April 2020) & $1 \longrightarrow$ & $3.60(1.89,6.87)$ & 15.42 \\
\hline Feng et al., (April 2020) & & $0.08(0.00,6.88)$ & 1.29 \\
\hline Subtotal $(\mathrm{I}-\mathrm{squared}=64.7 \%, \mathrm{p}=0.092)$ & 1 & $1.01(0.03,34.76)$ & 16.71 \\
\hline . & 1 & & \\
\hline ARBs & 1 & & \\
\hline Benelli et al., (April 2020) & & $3.13(1.70,5.76)$ & 15.82 \\
\hline Feng et al., (April 2020) & । & $0.25(0.05,1.18)$ & 7.19 \\
\hline Subtotal $($ I-squared $=88.6 \%, p=0.003)$ & $=$ & $0.98(0.08,11.57)$ & 23.01 \\
\hline . & 1 & & \\
\hline Overall $(\mathrm{I}$-squared $=77.4 \%, p=0.000$ ) & & $1.61(0.96,2.70)$ & 100.00 \\
\hline NOTE: Weights are from random effects analysis & i & & \\
\hline .001 & & & \\
\hline
\end{tabular}

FIGURE 9 Forest plot depicting pooled estimates for the association between use of ventilator and the three levels of renin-angiotensin system drug exposure (ACEls/ARBs, ACEls, ARBs)

in the respiratory tracts, which is the key entry system for COVID19 , is lacking. ${ }^{56}$ Furthermore, it should be noticed that alteration in angiotensin II level, which is only one substrate of ACE2's multiple substrates, is unlikely to result in any meaningful differences in ACE2 substrate load, hence its upregulation ${ }^{56}$; additionally, the fact that people from various sexes, ages, and races are all susceptible to COVID-19 infection suggests that physiological expression of ACE2 might already be sufficient for COVID-19 infection; thus any further ACE2 upregulation might not have effects on the risk/severity of COVID-19 infection. ${ }^{25}$ Together, these evidences indicate that the concerns around ACEIs/ARBs use in COVID-19 patients might be unjustifiable. On the other hand, the protective effect hypothesizes on ACEls/ARBs protecting against lung injury, through blockage of the harmful angiotensin II- AT1R axis, which gets activated by impairment of ACE2 activity as a result of ACE2's downregulation results from ACE2's binding with COVID-19 virus; additionally, the corresponding increase in angiotensin II and angiotensin I, due to ACEIs/ARBs use, would activate the protective axis and hence reduce COVID-19 viral pathogenicity. ${ }^{4}$ Genetic ACE2 polymorphism among some individuals has been also suggested as potential factor explaining, at least partially, the harmful effects on ACEIs/ARBs among COVId-19 patients ${ }^{58}$; but this needs further investigation.

\section{1 | Strengths and limitation}

We believe this study is the first to provide a systematic, comprehensive and updated evaluation of the effects of ACEIs/ARBs on all the reported COVID-19-related clinical outcomes including exploration of interclass differences between ACEls and ARBs as well as multiple subgroup analyses, although we do acknowledge that some of the subgroup analyses only had 1-2 studies for some of the studied outcomes such as ICU admission and Death/ICU admission. However, our study has limitations. Since all included studies were observational studies, the effect of confounding including residual confounders cannot be ruled out. There is also the possibility that new studies 
Study

ID
ICU admission or use of ventilator

\section{ACEIs/ARBs}

Bean et al., (May 2020)

Benelli et al., (April 2020)

Benelli et al., (April 2020)

Feng et al., (April 2020)

Mehta et al., (May 2020)

Mehta et al., (May 2020)

Yang et al., (May 2020)

Rentsch et al., (April 2020)

Richardson et al., (April 2020)

Richardson et al., (April 2020)

Subtotal $(\mathrm{I}$-squared $=83.2 \%, \mathrm{p}=0.000$ )

ACEls

Benelli et al., (April 2020)

Benelli et al., (April 2020)

Feng et al., (April 2020)

Dauchet et al., (May 2020)

Dauchet et al., (May 2020)

Subtotal $(\mathrm{I}$-squared $=75.2 \%, p=0.003$ )

\section{ARBs}

Benelli et al., (April 2020)

Benelli et al., (April 2020)

Feng et al., (April 2020)

Dauchet et al., (May 2020)

Dauchet et al., (May 2020)

Subtotal $(\mathrm{I}$-squared $=66.2 \%, \mathrm{p}=0.019$ )

Overall $($ I-squared $=77.1 \%, p=0.000)$

NOTE: Weights are from random effects analysis .001

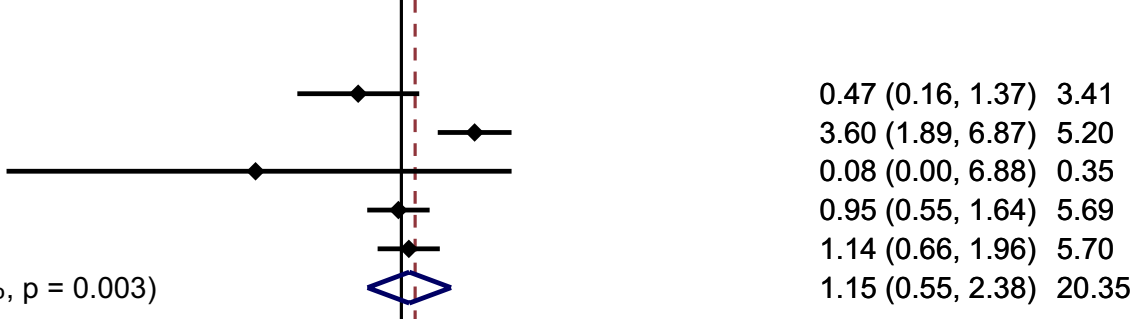

$0.95(0.44,2.07) 4.59$

$3.13(1.70,5.76) 5.37$

$0.25(0.05,1.18) 2.12$

$1.56(1.02,2.39) 6.28$

$1.63(1.07,2.51) 6.28$

$1.47(0.91,2.37) 24.63$

$1.27(0.97,1.66) \quad 100.00$

FIGURE 10 Forest plot depicting pooled estimates for the association between use of ventilator/Intensive Care Unit admission and the three levels of renin-angiotensin system drug exposure (ACEIs/ARBs, ACEIs, ARBs)

have been published since our review. However, we included nonpeer-reviewed articles published in medRxiv to help address this.

\section{5 | CONCLUSION}

There appears to be no evidence of association between ACEls/ARBs use and a wide range of COVID-19-related clinical outcomes. However, good quality evidence exists for ACEls/ARBs and higher odds of hospitalization, lower odds of death/ICU admission (as composite endpoint); but only low-quality evidence for higher ICU admission, ventilator use, hospital discharge and lower duration of hospital stay exists. Furthermore, there is evidence, albeit of poor quality, of differences between ACEls and ARBs with the latter being associated with significantly higher ICU admission but lower COVID-19 infection risk and severity. Given the continuing controversial and paradoxical clinical studies' findings and hypotheses, we believe it is necessary to continue to evaluate the effects of ACEIs/ARBs on COVID-19 clinical outcomes especially as more randomized studies are reported.

\section{6 | NOMENCLATURE OF TARGETS AND LIGANDS}

Key protein targets and ligands in this article are hyperlinked to corresponding entries in http://www.guidetopharmacology.org, 
the common portal for data from the IUPHAR/BPS Guide to PHARMACOLOGY, ${ }^{59}$ and are permanently archived in the Concise Guide to PHARMACOLOGY 2019/20. ${ }^{60}$

\section{ETHICS APPROVAL}

Not required.

\section{DISCLOSURE}

Nothing to declare.

\section{AUTHOR CONTRIBUTIONS}

Study conception and design: all authors; data collection and management: NA, AL; data analysis and interpretation: AK, BG; manuscript writing and drafting: $A K, N A$; manuscript reviewing and revising as well as providing constructive criticism and final approval: all authors.

\section{DATA AVAILABILITY STATEMENT}

The data that support the findings of this study are available from the corresponding author upon reasonable request.

\section{ORCID}

Amanj Kurdi iD https://orcid.org/0000-0001-5036-1988

\section{REFERENCES}

1. Zheng Y-Y, Ma Y-T, Zhang J-Y, et al. COVID-19 and the cardiovascular system. Nat Rev Cardiol. 2020;17:259-260.

2. Hoffmann M, Kleine-Weber H, Schroeder S, et al. SARS-CoV-2 cell entry depends on ACE2 and TMPRSS2 and is blocked by a clinically proven protease inhibitor. Cell. 2020;181:271-280.e8.

3. Zhou F, Yu T, Du R, et al. Clinical course and risk factors for mortality of adult inpatients with COVID-19 in Wuhan, China: a retrospective cohort study. Lancet. 2020;395:1054-1062.

4. Kreutz R, Algharably EAE-H, Azizi M, et al. Hypertension, the renin-angiotensin system, and the risk of lower respiratory tract infections and lung injury: implications for COVID-19 European Society of Hypertension COVID-19 Task Force Review of Evidence. Cardiovasc Res. 2020;116:1688-1699.

5. Driggin E, Madhavan MV, Bikdeli B, et al. Cardiovascular considerations for patients, health care workers, and health systems during the COVID-19 pandemic. J Am Coll Cardiol. 2020;75:2352-2371.

6. Du R-H, Liang L-R, Yang C-Q, et al. Predictors of mortality for patients with COVID-19 pneumonia caused by SARS-CoV-2: a prospective cohort study. Eur Respir J. 2020;55:2002439.

7. World Health Organization. COVID-19 and the use of angiotensin-converting enzyme inhibitors and receptor blockers: scientific brief, 7 May 2020. Geneva: World Health Organization; 2020.

8. Gilstrap LG, Fonarow GC, Desai AS, et al. Initiation, continuation, or withdrawal of angiotensin-converting enzyme inhibitors/angiotensin receptor blockers and outcomes in patients hospitalized with heart failure with reduced ejection fraction. J Am Heart Assoc. 2017;6:e004675.

9. Sparks M, Hiremath S. The coronavirus conundrum: ACE2 and hypertension edition. NephJC. 2020.

10. Vaduganathan M, Vardeny $\mathrm{O}$, Michel $\mathrm{T}$, et al. Renin-angiotensin-aldosterone system inhibitors in patients with Covid-19. N Engl J Med. 2020;382:1653-1659.
11. International Society of Hypertension. A statement from the International Society of Hypertension on COVID-19 2020 [cited 2020 15th June]. Available from https://ish-world.com/news/a/Astatement-from-the-International-Society-of-Hypertension-onCOVID-19/

12. Abena PM, Decloedt EH, Bottieau E, et al. Chloroquine and hydroxychloroquine for the prevention or treatment of novel coronavirus disease (COVID-19) in Africa: caution for inappropriate off-label use in healthcare settings. Am J Trop Med Hyg. 2020;102:1184-1188.

13. Haque M, Islam S, Iqbal S, et al. Availability and price changes of potential medicines and equipment for the prevention and treatment of COVID-19 among pharmacy and drug stores in Bangladesh; findings and implications. Bangladesh J Med Sci. 2020;19:S 36-S 50.

14. Horby P, Landray M. No clinical benefit from use of hydroxychloroquine in hospitalised patients with COVID-19 2020 [cited 2020 15th June]. Available from https://www.recoverytrial.net/news/ statement-from-the-chief-investigators-of-the-randomised-evalu ation-of-covid-19-therapy-recovery-trial-on-hydroxychloroquine5-june-2020-no-clinical-benefit-from-use-of-hydroxychloroquinein-hospitalised-patients-with-covid-19.

15. World Health Organization. WHO discontinues hydroxychloroquine and lopinavir/ritonavir treatment arms for COVID-19 2020 [cited 2020 10th July]. Available from https://www.who.int/newsroom/detail/04-07-2020-who-discontinues-hydroxychloroquineand-lopinavir-ritonavir-treatment-arms-for-covid-19.

16. National Institute of Health. NIH halts clinical trial of hydroxychloroquine 2020 [cited 2020 24th June]. Available from https:// www.nhlbi.nih.gov/news/2020/nih-halts-clinical-trial-hydroxychl oroquine

17. Meng J, Xiao G, Zhang J, et al. Renin-angiotensin system inhibitors improve the clinical outcomes of COVID-19 patients with hypertension. Emerg Microbes Infect. 2020;9:757-760.

18. Liu Y, Huang F, Xu J, et al. Anti-hypertensive Angiotensin II receptor blockers associated to mitigation of disease severity in elderly COVID-19 patients. medRxiv. 2020;2020:2020.03.20.20039586.

19. Feng Y, Ling Y, Bai T, et al. COVID-19 with different severities: a multicenter study of clinical features. Am J Respir Crit Care Med. 2020;201:1380-1388.

20. Zhang P, Zhu L, Cai J, et al. Association of inpatient use of angiotensin converting enzyme inhibitors and angiotensin II receptor blockers with mortality among patients with hypertension hospitalized with COVID-19. Circ Res. 2020;126:1671-1681.

21. Mancia G, Rea F, Ludergnani M, et al. Renin-angiotensin-aldosterone system blockers and the risk of Covid-19. N Engl J Med. 2020;382:2431-2440.

22. Reynolds HR, Adhikari S, Pulgarin C, et al. Renin-angiotensin-aldosterone system inhibitors and risk of Covid-19. N Engl J Med. 2020;382:2441-2448.

23. Richardson S, Hirsch JS, Narasimhan M, et al. Presenting characteristics, comorbidities, and outcomes among 5700 patients hospitalized with COVID-19 in the New York City area. JAMA. 2020;323:2052-2059.

24. Li J, Wang X, Chen J, et al. Association of renin-angiotensin system inhibitors with severity or risk of death in patients with hypertension hospitalized for coronavirus disease 2019 (COVID-19) infection in Wuhan, China. JAMA Cardiol. 2020;5:825-830.

25. Yang G, Tan Z, Zhou L, et al. Effects of angiotensin II receptor blockers and ACE (Angiotensin-Converting Enzyme) inhibitors on virus infection, inflammatory status, and clinical outcomes in patients with COVID-19 and hypertension: a single-center retrospective study. Hypertension (Dallas, Tex: 1979). 2020;76:51-58.

26. Zeng Z, Sha T, Zhang Y, et al. Hypertension in patients hospitalized with COVID-19 in Wuhan, China: a single-center retrospective observational study. medRxiv. 2020;2020:2020.04.06.20054825. 
27. Ip A, Parikh K, Parrillo JE, et al. Hypertension and ReninAngiotensin-aldosterone system inhibitors in patients with covid19. medRxiv. 2020;2020:2020.04.24.20077388.

28. Guo T, Fan Y, Chen M, et al. Cardiovascular implications of fatal outcomes of patients with coronavirus disease 2019 (COVID-19). JAMA Cardiol. 2020;5:811-818.

29. Grover A, Oberoi M. A systematic review and meta-analysis to evaluate the clinical outcomes in COVID-19 patients on angiotensin converting enzyme inhibitors or angiotensin receptor blockers. medRxiv. 2020. https://doi.org/10.1101/2020.04.29.20085787

30. Mackey K, King VJ, Gurley S, et al. Risks and impact of Angiotensinconverting enzyme inhibitors or angiotensin-receptor blockers on SARS-CoV-2 infection in adults: a living systematic review. Ann Intern Med. 2020;173:195-203.

31. Innovation $\mathrm{VH}$. Covidence systematic review software. Australia: Veritas Health Innovation Melbourne; 2016.

32. Lo CK-L, Mertz D, Loeb M. Newcastle-Ottawa Scale: comparing reviewers' to authors' assessments. BMC Med Res Methodol. 2014;14:45.

33. Wells G, Shea B, O'Connell D, et al. Newcastle-Ottawa quality assessment form for cohort studies. 2014;E17-E18.

34. Almeida PH, Silva TB, de Assis AF, et al. Quality of life of patients with type 1 diabetes mellitus using insulin analog glargine compared with NPH insulin: a systematic review and policy implications. Patient-Patient-Centered Outcomes Res. 2018;11:377-389.

35. Bland JM, Altman DG. The odds ratio. BMJ. 2000;320:1468.

36. Kelley GA, Kelley KS. Statistical models for meta-analysis: a brief tutorial. World J Methodol. 2012;2:27.

37. Higgins JP, Thompson SG, Deeks JJ, et al. Measuring inconsistency in meta-analyses. BMJ. 2003;327:557-560.

38. Egger M, Smith GD, Schneider M, et al. Bias in meta-analysis detected by a simple, graphical test. BMJ. 1997;315:629-634.

39. Higgins JP, Green S. Cochrane Handbook for Systematic Reviews of Interventions Version 5.1. 0 [updated March 2011]. The Cochrane Collaboration: the Cochrane Collaboration; 2011 [cited 2020 13th September]. Available from https://handbook-5-1.cochrane. org/

40. Bean D, Kraljevic Z, Searle T, et al. ACE-inhibitors and Angiotensin-2 Receptor Blockers are not associated with severe SARS- COVID19 infection in a multi-site UK acute Hospital Trust. medRxiv. 2020;2020:2020.04.07.20056788.

41. Benelli G, Buscarini E, Canetta C, et al. SARS-COV-2 comorbidity network and outcome in hospitalized patients in Crema, Italy. medRxiv. 2020;2020:2020.04.14.20053090.

42. Dauchet L, Lambert M, Gauthier V, et al. ACE inhibitors, AT1 receptor blockers and COVID-19: clinical epidemiology evidences for a continuation of treatments. The ACER-COVID study. medRxiv. 2020;2020:2020.04.28.20078071.

43. Rentsch CT, Kidwai-Khan F, Tate JP, et al. Covid-19 testing, hospital admission, and intensive care among 2,026,227 United States Veterans Aged 54-75 Years. medRxiv. 2020;2020:2020.04.09.20059964.

44. Mehta N, Kalra A, Nowacki AS, et al. Association of use of angiotensin-converting enzyme inhibitors and angiotensin II receptor blockers with testing positive for coronavirus disease 2019 (COVID-19). JAMA Cardiol. 2020;5:1020-1026.

45. Bravi F, Flacco ME, Carradori T, et al. Predictors of severe or lethal COVID-19, including Angiotensin Converting Enzyme Inhibitors and Angiotensin II Receptor Blockers, in a sample of infected Italian citizens. medRxiv. 2020;2020:2020.05.21.20109082.

46. Khera R, Clark C, Lu Y, et al. Association of angiotensin-converting enzyme inhibitors and angiotensin receptor blockers with the risk of hospitalization and death in hypertensive patients with coronavirus disease-19. medRxiv. 2020;2020:2020.05.17.20104943.
47. Giorgi Rossi P, Marino M, Formisano D, et al. Characteristics and outcomes of a cohort of SARS-CoV-2 patients in the Province of Reggio Emilia, Italy. medRxiv. 2020;2020:2020.04.13.20063545.

48. Yan $\mathrm{H}$, Valdes AM, Vijay A, et al. Role of drugs affecting the renin-angiotensin-aldosterone system on susceptibility and severity of COVID-19: a large case-control study from Zheijang Province, China. medRxiv. 2020;2020:2020.04.24.20077875.

49. Chodick G, Nutman A, Yiekutiel N, et al. Angiotension-converting enzyme inhibitors and angiotensin-receptor blockers are not associated with increased risk of SARS-CoV-2 infection. J Travel Med. 2020;27:1-3.

50. De Spiegeleer A, Bronselaer A, Teo JT, et al. The effects of ARBs, ACEls and statins on clinical outcomes of COVID19 infection among nursing home residents. medRxiv. 2020;2020:2020.05.11.20096347.

51. Feng Z, Li J, Yao S, et al. The use of adjuvant therapy in preventing progression to severe pneumonia in patients with coronavirus disease 2019. A Multicenter Data Analysis. medRxiv. 2020;2020:2020.04.08.20057539.

52. Khawaja AP, Warwick AN, Hysi PG, et al. Associations with Covid19 hospitalisation amongst 406,793 adults: the UK Biobank prospective cohort study. medRxiv. 2020;2020:2020.05.06.20092957.

53. Raisi-Estabragh Z, McCracken C, Ardissino M, et al. Non-white ethnicity, male sex, and higher body mass index, but not medications acting on the renin-angiotensin system are associated with coronavirus disease 2019 (COVID-19) hospitalisation: review of the first 669 cases from the UK BIOBANK. medRxiv. 2020. https://doi. org/10.1101/2020.05.10.20096925

54. Rhee SY, Lee J, Nam H, et al. Effects of a DPP-4 inhibitor and RAS blockade on clinical outcomes of patients with diabetes and COVID-19. medRxiv. 2020;2020:2020.05.20.20108555.

55. Rico-Mesa JS, White A, Anderson AS. Outcomes in patients with COVID-19 infection taking ACEI/ARB. Curr Cardiol Rep. 2020;22:1-4.

56. Danser AJ, Epstein M, Batlle D. Renin-angiotensin system blockers and the COVID-19 pandemic: at present there is no evidence to abandon renin-angiotensin system blockers. Hypertension. 2020;75:1382-1385

57. Esler M, Esler D. Can angiotensin receptor-blocking drugs perhaps be harmful in the COVID-19 pandemic? J Hypertens. 2020;38:781-782.

58. Fang L, Karakiulakis G, Roth M. Are patients with hypertension and diabetes mellitus at increased risk for COVID-19 infection? Lancet Respir Med. 2020;8:e21.

59. Harding SD, Sharman JL, Faccenda E, et al. The IUPHAR/BPS Guide to PHARMACOLOGY in 2018: updates and expansion to encompass the new guide to IMMUNOPHARMACOLOGY. Nucleic Acids Res. 2018;46(D1):D1091-D1106.

60. Alexander SP, Fabbro D, Kelly E, et al. The concise guide to pharmacology 2019/20: enzymes. Br J Pharmacol. 2019;176:S297-S396.

\section{SUPPORTING INFORMATION}

Additional supporting information may be found online in the Supporting Information section.

How to cite this article: Kurdi A, Abutheraa N, Akil L, Godman B. A systematic review and meta-analysis of the use of renin-angiotensin system drugs and COVID-19 clinical outcomes: What is the evidence so far? Pharmacol Res Perspect. 2020;e00666. https://doi.org/10.1002/prp2.666 